\title{
Physiological and Biochemical Zoology \\ The effects of weather conditions on oxidative stress, oxidative damage and antioxidant capacity in a wild-living mammal, the European badger (Meles meles) --Manuscript Draft--
}

\begin{tabular}{|c|c|}
\hline Manuscript Number: & 17099R2 \\
\hline Full Title: & $\begin{array}{l}\text { The effects of weather conditions on oxidative stress, oxidative damage and } \\
\text { antioxidant capacity in a wild-living mammal, the European badger (Meles meles) }\end{array}$ \\
\hline Short Title: & Weather interactions with oxidative stress \\
\hline Article Type: & Research Paper \\
\hline Corresponding Author: & $\begin{array}{l}\text { Chris Newman, DPhil, MPhil. BSc. } \\
\text { University of Oxford } \\
\text { Abingdon, Oxfordshire UNITED KINGDOM }\end{array}$ \\
\hline \multicolumn{2}{|l|}{$\begin{array}{l}\text { Corresponding Author Secondary } \\
\text { Information: }\end{array}$} \\
\hline Corresponding Author's Institution: & University of Oxford \\
\hline \multicolumn{2}{|l|}{$\begin{array}{l}\text { Corresponding Author's Secondary } \\
\text { Institution: }\end{array}$} \\
\hline First Author: & Kirstin Bilham \\
\hline \multicolumn{2}{|l|}{ First Author Secondary Information: } \\
\hline \multirow[t]{7}{*}{ Order of Authors: } & Kirstin Bilham \\
\hline & Chris Newman, DPhil, MPhil. BSc. \\
\hline & Christina D Buesching \\
\hline & Michael J Noonan \\
\hline & Amy Boyd \\
\hline & Adrian L Smith \\
\hline & David W Macdonald \\
\hline \multicolumn{2}{|c|}{ Order of Authors Secondary Information: } \\
\hline Abstract: & $\begin{array}{l}\text { Wild-living animals are subject to weather variability that may cause the generation of } \\
\text { reactive oxygen species, resulting in oxidative stress and tissue damage, potentially } \\
\text { driving demographic responses. Our three-year field study investigated the effects of } \\
\text { seasonal weather conditions on biomarkers for oxidative stress, oxidative damage and } \\
\text { antioxidant defence in the European badger (Meles meles). We found age-class } \\
\text { effects: cubs were more susceptible to oxidative stress and oxidative damage than } \\
\text { adults, especially very young cubs in the spring, when they also exhibited lower } \\
\text { antioxidant biomarkers than adults. Although previous studies have found that } \\
\text { intermediate spring and summer rainfall and warmer temperatures favor cub survival, } \\
\text { counter-intuitively these conditions were associated with more severe oxidative } \\
\text { damage. Oxidative damage was high in cubs even when antioxidant biomarkers were } \\
\text { high. In contrast, adult responses accorded with previous survival analyses. Wetter } \\
\text { spring and summer conditions were associated with higher oxidative damage, but also } \\
\text { with higher antioxidant biomarkers. Autumnal weather did not vary substantially from } \\
\text { normative values and thus effects were muted. Winter carry over effects were partially } \\
\text { evident, with drier and milder conditions associated with greater oxidative damage in } \\
\text { the following spring, but also with higher antioxidant capacity. Plausibly warmer } \\
\text { conditions promoted more badger activity, with associated metabolic costs at a time of } \\
\text { year when food supply is limited. Modeling biomarkers against projected climate } \\
\text { change scenarios predicted greater future risks of oxidative damage, although not } \\
\text { necessarily exceeding antioxidant capacity. This interdisciplinary approach } \\
\text { demonstrates that individual adaptive physiological responses are associated with } \\
\text { variation in natural environmental conditions. }\end{array}$ \\
\hline
\end{tabular}




\section{Abstract}

2 Wild-living animals are subject to weather variability that may cause the generation of reactive oxygen species, resulting in oxidative stress and tissue damage, potentially driving demographic responses. Our three-year field study investigated the effects of seasonal weather conditions on biomarkers for oxidative stress, oxidative damage and antioxidant defence in the European badger (Meles meles). We found age-class effects: cubs were more susceptible to oxidative stress and oxidative damage than adults, especially very young cubs in the spring, when they also exhibited lower antioxidant biomarkers than adults. Although previous studies have found that intermediate spring and summer rainfall and warmer temperatures favor cub survival, counter-intuitively these conditions were associated with more severe oxidative damage. Oxidative damage was high in cubs even when antioxidant biomarkers were high. In contrast, adult responses accorded with previous survival analyses. Wetter spring and summer conditions were associated with higher oxidative damage, but also with higher antioxidant biomarkers. Autumnal weather did not vary substantially from normative values and thus effects were muted. Winter carry over effects were partially evident, with drier and milder conditions associated with greater oxidative damage in the following spring, but also with higher antioxidant capacity. Plausibly warmer conditions promoted more badger activity, with associated metabolic costs at a time of year when food supply is limited. Modeling biomarkers against projected climate change scenarios predicted greater future risks of oxidative damage, although not necessarily exceeding antioxidant capacity. This interdisciplinary approach demonstrates that individual adaptive physiological responses are associated with variation in natural environmental conditions.

Key Words: Antioxidant, Climate Change, Eco-physiology, Reactive Oxygen Species, Oxidative Damage, Oxidative Stress, Weather Conditions. 
When wild animals experience low food availability or disease, changes in their energetic or immune activity can lead to increased metabolic stress, promoting the generation of reactive oxygen species (ROS) (Leeuwenburgh and Heinecke 2001). Although animals produce endogenous antioxidant molecules (e.g. glutathione), or enzymes (e.g. peroxidases; supplemented by their consumption of exogenous dietary antioxidants) to neutralize the unpaired electron in ROS, oxidative stress (OS) and oxidative damage (OD) can occur if antioxidant defences are exceeded (Matés et al. 2002). Consequently, when evolutionarily novel stressors arise from Human Induced Rapid Environmental Change (HIREC; Sih 2013), these can further exacerbate the physiological burden wild-living animals must cope with (Sies 1997), potentially compromising their defence systems. Weather conditions are often intrinsically linked to food availability, foraging success, thermoregulatory costs and metabolic rates (Kronfeld-Schor and Dayan 2013); conditions likely to influence OS and OD. Furthermore, there can be cumulative 'carry-over effects' (COE; Harrison et al. 2011), where weather conditions in one season affect an individual's subsequent performance, provided it continues to survive. Consequently, if weather becomes increasingly unseasonable, variable and extreme, as predicted under climate change scenarios (Allen et al. (IPCC), 2014; see also Parmesan, Root and Willig 2000), this may exceed species' coping capacities (Smit et al. 2000), with implications for fitness and survival (White 2008).

Here, we undertake an inter-disciplinary approach (White \& Ward 2011), using a medium-sized generalist carnivore, the European badger (henceforth 'badger') to explore how OS may operate mechanistically as the currency (sensu, Metcalfe and Alonso-Alvarez 2010) through which weather stress can affect eco-physiology (Costantini et al. 2010). We 
51 (RBCs) to survive a free radical attack ex vivo; Kurata et al. 1993; Bize et al. 2008), OD (using lipid peroxidation, Mylonas and Kouretas 1998; via plasma malondialdehyde, MDA, Nielsen et al. 1997), antioxidant capacity (AOX) and enzymatic antioxidant capacity (peroxidise, PER; see Somogyi et al. 2007). This expands on previous research identifying weatherinduced macro-demographic responses for this species (inter alia), as-well-as individual declines in body-condition and reproductive success (Newman et al. 2017; for broader discussion see Newman and Macdonald 2015). Specifically, badgers provide an informative model for studying responses to weather conditions because they preferentially forage for earthworms (Lumbricus spp.; see Newman et al. 2017), the availability of which is tied tightly to soil microclimate and prevailing weather (Curry 2004). However, badgers reside in communal burrows (termed setts) and, provided they have sufficient body-fat reserves, they can stay underground during periods of inclement weather and/or poor foraging conditions to mitigate net energy loss (Noonan et al. 2014; 2015). Consequently badgers undergo frequent short-term periodic swings in foraging activity, foraging success and body-condition, ultimately attempting to replenish depleted somatic reserves (Newman et al. 2011). This high metabolic turn-over, linked directly to variation in weather, is likely to generate ROS (Leeuwenburgh and Heinecke 2001). Under net-negative foraging conditions, when badgers do not meet their immediate energetic needs, they catabolize fat reserves (Domingo-Roura et al. 2001; Newman et al. 2011). Generally fat catabolism generates ROS (Morales et al. 2004) and causes redox imbalance, leading to increased levels of OD, despite upregulation of antioxidant enzymes (Vijayakumar et al. 2004). Once fat reserves are depleted, catabolizing muscle (protein) can further increase OS (Eisler et al. 2004; Finn and Dice 2006). Certainly, body-fat depletion adversely affects badger health (Domingo-Roura et al. 2001), over-winter survival (Macdonald and Newman 2002) and embryonic implantation (Woodroffe 1995; 
Winter weather is especially critical for badgers, with frost making earthworms unavailable (Newman et al. 2017) and badgers use periods of torpor to mitigate food scarcity (Newman et al. 2011). Such scarcity has been linked with lower over-winter survival rates (Macdonald and Newman 2002), as-well-as lower cub recruitment into the adult population (Nouvellet et al. 2013). This leads us to predict that: (i) biomarkers of OS/OD and antioxidant capacity may be associated seasonal weather variation; (ii) individuals in poorer bodycondition might exhibit higher OS/OD biomarker levels; and (iii) winter weather COE may affect individual OS/OD and antioxidant levels in the following spring. We consider, however, that OS/OD could occur even without apparent loss of body-condition over a season, due to the effective compensation of fat reserves.

Previous work in this same badger population by Macdonald and Newman (2002) identified that spring rainfall was critical to cub survival, with drought conditions leading to higher mortality rates (see also Macdonald et al. 2010). Building on this, Nouvellet et al. (2013) found distinct age-class specific responses, where cub survival probability was highest in years with intermediate annual rainfall (neither too wet nor too dry; a negative quadratic relationship) and intermediate temperature; whereas adult survival probability was greater in wetter years. These leads to a series of age-related predictions, positing that (iv) cubs and elderly badgers may be more vulnerable to OS/OD than prime-age adults, whereas (v) adults may benefit from more rainfall if weather interactions with OS/ OD biomarkers follow similar patterns to mortality effects. Furthermore, (vi) cub may experience more severe OS/OD effects in years with more extreme weather. Linked to this, we further predict that (vii) different OS phenotypes may be favoured under different weather conditions in different years (sensu Metcalfe and Alonso-Alvarez 2010).

Finally, we use emergent interactions between these biomarkers and weather conditions to parameterize simulations of how future weather conditions, according to the 
101 IPCCs SRES climate change emissions scenarios (Murphy et al. 2009), might affect OS and 102 OD. Herein we propose that this approach could provide a new tool for anticipating the 103 effects of climate change on wildlife more broadly, better enabling appropriate and effective 104 conservation action (Beaulieu et al. 2013). 


\section{Methods}

107 Badgers are highly tractable, enabling frequent recapture and large enough to yield sufficient blood volumes, also for repeat sampling. For this study, a total of 220 unique individuals were caught as part of ongoing socio-ecological population monitoring in Wytham Woods, UK (see Macdonald et al. 2015). Briefly, marked (tattooed) individuals were captured seasonally (spring (end of May - start of June) 2012-14, summer (end of August) 2012-14, autumn (mid-November) 2012-13) sedated, measured and blood sampled, then given sufficient time to recover from sedation prior to release back at their sett of capture; for full handling protocol see Sun et al. (2015). Over the study period, these 220 individuals were sampled between 1 and 11 times (median =2), yielding a total of 564 unique capture records and blood samples (Table 1). A body condition index (BCI) was calculated as: $\log ($ weight $) / \log ($ length) (following Noonan et al. 2014). Age was known from year of birth and divided into classes: Cubs $<1$ yr; prime adults $1-5$ yr; old adults $\geq 6$. Sex was also recorded.

\section{Oxidative stress assays}

122 For details of assay methodologies, see Supporting on-line information, Appendix 1, but briefly: Total antioxidant capacity (AOX) was measured as non-enzymatic plasma antioxidant capacity (STA-360, Cell Biolabs, San Diego, USA) and enzymatic antioxidant capacity via peroxidase (PER; STA-344, Cell Biolabs, San Diego). As a biomarker of OD, lipid peroxidation (LP) was measured as malondialdehyde accumulation in plasma (STA330, Cell Biolabs, San Diego, USA) and red blood cell 1/2-life (RBC 1/2-life) was used as a 
biomarker indicating resistance to OS, calculated as the time it took $50 \%$ of RBCs to lyze in the presence of an oxidant (Kirial, Courernon, France).

\section{Weather data}

Freely available weather records were obtained from the University of Oxford's Radcliffe Meteorological Station. Metrics of rainfall (total $\mathrm{mm} / \mathrm{month}$ ); minimum temperature (monthly mean daily minimum temperatures, in degrees Celsius); maximum temperature (monthly mean daily maximum temperatures, in degrees Celsius); and frost (number of days of frost/month) were extracted from this dataset. Mean weather conditions, used to analyze corresponding seasonal trapping sessions, were defined as: Winter: December - February (i.e. December 2011 to February 2012, inclusive, defines winter 2012); Spring: March May; Summer: June-August; Autumn: September - November. Details of how weather in these seasons compared to 30 year average conditions are presented in Table 2.

\section{Principal weather components}

We used principal component analyses (PCA), conducted with scaling, to control for collinearity between weather metrics (for details see Appendix 2). This resulted in the retention of two principal components (PC) as predictive weather variables. For the PCA pertaining to seasonal analyses, factor loadings for temperature were the most influential contributors to the PC1 axis. Loadings were positive, thus higher values of PC1 correspond to higher temperatures. PC2 had a positive rainfall loading, where higher values correspond to wetter conditions. These components are henceforth referred to as PCtemp and PCrain.

For our COE analyses, PC1 factor loadings (PCtemp) included maximum temperature, minimum temperature and number of days of frost over the winter, such that 
higher values of PC1 correspond to lower temperatures and more frost. PC2 (PCrain) had a negative rainfall loading where higher values correspond to drier weather.

\section{Modeling seasonal weather effects on $O S, O D$ and antioxidant defences}

To identify predictors of variance in biomarkers, we built four global models that included these principal components, along with season, BCI, age-class and sex as fixed effects:

AOX $=f($ Age-class*PCrain*Season+Age-class*PCtemp*Season+Sex+BCI $)$

$\log (\mathrm{LP})=f($ Age-class $*$ PCrain $*$ Season + Age-class $*$ PCtemp $*$ Season + Sex + BCI $)$

PER $=f($ Age-class $*$ PCrain $*$ Season+Age-class*PCtemp*Season+Sex+BCI $)$

RBC 1/2-life $=f($ Age-class $*$ PCrain*Season+Age-class $*$ PCtemp $*$ Season+Sex+BCI $)$

To account for repeat sampling of individuals, badger ID was included as a random effect.

We note that while our fixed effects were subject to temporal autocorrelation, the coarse scale at which these were measured did not result in any significant violation of the assumption of independence (see Appendix 2). LP values were log transformed to correct for heteroscedasticity. From these global models, we specified subsets of candidate models comprised of all possible combinations of fixed effects, both with and without interaction terms. We then used small sample size corrected Akaike's information criterion (AICc), to rank these candidates according to their statistical support (Burnham et al. 2011), additionally calculating the delta $\operatorname{AICc}\left(\Delta_{i}\right)$, in relation to the highest-ranking model and the Akaike (or model) weight (w) for each model using the R package MuMIn (v. 1.15.6; Barton 2016). Following Anderson (2008), rather than using $\Delta_{\mathrm{i}}$ cut-off values, we applied weightbased averaging over all candidate models. From this, we derived averaged parameter estimates $(\theta)$, calculated by averaging their values over all candidate models that included the 
parameter of interest, weighted by $w$, and their $95 \%$ confidence intervals (CI). We also calculated the 'relative influence' (RI) of each variable as the summation of $w$ across all models that included the variable of interest (Burnham \& Anderson, 2002).

\section{Modeling winter weather COE on OS and antioxidant defences}

Badgers were not trapped during winter due to a legal closed season to avoid stressing pregnant females (Protection of Badgers Act 1992). Instead we modeled the COE of winter weather on OS measurements in following the spring. Similar models were built to examine the COE of winter weather on spring OS measurements in adults (including cubs recruited from the previous year). Badger ID and age class were included as random effects to account for repeat sampling and for any differences between age classes (prime vs old), and AICc was derived for each model along with relative model weight $(\mathrm{W})$.

$\mathrm{AOX}=f($ PCrain + PCtemp $+\mathrm{Sex}+\mathrm{BCI})$

$\log (\mathrm{LP})=f($ PCrain + PCtemp + Sex + BCI $)$

$\mathrm{PER}=f($ PCrain + PCtemp + Sex + BCI $)$

RBC 1/2-life $=f($ PCrain + PCtemp + Sex + BCI $)$

Model selection and averaging was then applied as described above. Note, cubs that survived the winter into the spring of the following were then included here as adults - age $>1$ year.

\section{Climate change projections}

We used these predictive models to parameterize simulations of how future climate change might affect OS, OD and AOX. Using the UK Climate Projections 2009 web interface (UKCP09; Murphy et al. 2009), we simulated 1000 projections of future seasonal weather 
conditions for the $25 \mathrm{~km}^{2}$ area around Wytham Woods into the years 2070-2099. UKCP09 projections were based on the IPCCs SRES low emissions (i.e., the B1 scenario, which predicts 500 to $600 \mathrm{ppm} \mathrm{CO}_{2}$, a 1.1 to $2.9^{\circ} \mathrm{C}$ rise in mean temperature and no significant

201

202

203

204

205

206

207

208

209

210

211

212 trends in precipitation) and high emissions scenarios (i.e., the A1F1 scenario, which predicts 550 to $750 \mathrm{ppm} \mathrm{CO}_{2}$, a 2.4 to $6.4{ }^{\circ} \mathrm{C}$ rise in mean temperature and no significant trends in precipitation; Nakicenovic and Swart, 2005). We note that although more recent 'representative concentration pathway' (RCP) models have since replaced the SRES emissions scenarios (Moss et al. 2010), recent analyses have demonstrated how the UKCP09 projections still provide reliable projections (Sexton et al. 2016). Using each of these weather projections and our predictive models, we estimated 1000 potential biomarker responses using the predict() function in the R environment (v. 3.3.2; R Core Team 2016). We acknowledge, however, that although trends in responses can be considered as robust, both our parameter estimates and climate predictions are subject to modeling error and therefore interpretations should be made cautiously. 
214 Short-term observational studies of natural weather effects are always hostage to fortune,

215 because substantial variation may not occur within the study period, nevertheless our study 216 years included sufficient weather deviation from long-term normative values to show 217 meaningful effects on biomarkers (Table 2).

Analysis of seasonal weather effects on $O S, O D$ and $A O X$

$\underline{\text { Yearly cub survival rate }}$

Summary statistics for weather conditions are presented in Table 2 and for biomarkers in

Table 3. The three study years included substantially different cub cohort sizes with different survival rates. In 2012, a total of 41 cubs were caught, of which 20 (49\%) survived to adulthood. This was despite spring and summer weather both being considerably wetter than the long-term mean $(1.45 \times$ and $2.15 \times$ greater rainfall respectively). Subsequently, in 2013 , the winter was cold, with twice the normal number of frost days ( 50 vs the long-term mean of 26), followed by a cool spring (only $0.75 \times$ the long-term mean) and a drought summer that received only half of the normal rainfall. In this more challenging year, year only 28 cubs were caught, with 12 (43\%) surviving to adulthood. In 2014, the winter was mild (just 5 frost days) and very wet, with twice the normal rainfall and although 60 cubs were caught, only 22 (37\%) survived to adulthood, despite normative weather conditions throughout the rest of that year.

Of the modeled parameters, PCtemp, season, age-class*PCrain, PCrain*season, age- 
in AOX (Table 4). Sex had no distinct effect on AOX, or indeed on any other biomarker. For

237 cubs, AOX was lower when spring rainfall deviated from the long-term mean in either

238

239 direction and with cooler temperatures (Figure 1); conditions also associated with less interindividual variation. This occurred although we observed only modest spring rainfall variation from the long-term mean (with 2012 wettest, at $1.45 \times$ the rainfall of long-term mean), with no substantial variation in spring temperature. Cub AOX showed no significant associations with summer weather (see top row of Figure 1), despite very wet summer conditions in $2012(2.15 \times$ the mean rainfall) and drought in 2013 (only $0.2 \times$ the mean rainfall); albeit that the least inter-individual variability occurred when rainfall was abnormal.

Our dataset included minimal autumn weather variation, with only 2012 deviating substantially from normative rainfall $(1.41 \times$ the rainfall of long-term mean $)$ and no substantial temperature deviation; these conditions were associated with relatively low autumnal cub AOX (see Table 3).

Cub AOX was lower than adult AOX in the spring, except in the dry, cold spring of 2013, when cub levels almost equaled adult levels. For prime adults, spring AOX was lowest in 2013, which had normal rainfall and cooler temperatures; whereas for old adults AOX was lower in spring 2012, with wetter conditions (1.45× the mean rainfall). Prime- and old- adults exhibited similar AOX in summer, being lower with drier, warmer conditions. In autumn AOX was lower with cooler, wetter conditions - although linked to greater inter-individual variation.

\section{$\underline{\text { Antioxidant enzymes - peroxidase (PER) }}$}

Of the modelled parameters, age-class, PCrain and PCtemp, age-class*season, PCrain* season and the 3-way interaction PCtemp*age-class*season contributed significantly to variation in peroxidase (Table 4). In spring, cub and adult PER tended to be lower with less 
rainfall (Figure 1, second row). Inter-individual variability (Table 3) was greatest for cubs in the wettest year (2012); whereas inter-individual variability for both adult age-classes tended to be lower with drier conditions.

In summer, cubs exhibited similar mean PER levels between years, but with higher inter-individual variation with intermediate rainfall; whereas PER was highest for adults in the wettest summer $(2012 ; 2.15 \times$ the mean rainfall). Low inter-individual variation was also associated with lower PER. In autumn, cubs and adults again showed similar responses, with lower PER occurring with slightly wetter, cooler conditions. For adults, high inter-individual variability was again associated with high PER.

\section{$\underline{\text { Oxidative damage - lipid peroxidation (LP) }}$}

Of the modeled parameters, age-class, PCrain, PCtemp, season, PCrain*season, PCtemp*season contributed significantly to variation in LP (Table 4). Spring LP levels were higher for cubs than for adults. LP was highest in 2014, which had the warmest minimum temperature among study years $(1.12 \times$ warmer than the long-term mean; $1.07 \times$ warmer than the long-term mean maximum temperature), but with typical rainfall (Figure 1, third row). Peak inter-individual variability also occurred with these conditions. In summer, cub LP was higher with intermediate rainfall. Similar cub LP levels continued into the autumn, although greater inter-individual variability was apparent in 2012 across a larger annual cohort, when rainfall was $1.41 \times$ greater than the long-term mean and temperatures were cool.

Prime- and old- adults exhibited similar LP associations with weather. Spring LP levels were higher with intermediate rainfall and higher temperature. In summer, LP was again higher with intermediate rainfall, which also associated with the greatest inter- 
individual variability. In autumn, inter-individual variability was substantial under all conditions.

\section{$\underline{\text { Resistance to oxidative stress - Red Blood Cell half-life (RBC 1/2-life) }}$}

Of the modeled parameters, age class, Age class*PCrain, Age class*PCtemp, Age class*Season and Age class*PCrain*season contributed significantly to variation in RBC 1/2life (Table 4). There was little absolute difference between cub and adult RBC $1 / 2$-life. For cubs, spring RBC 1/2-life was shortest in the coldest year (2012), whereas warmer temperatures were associated with greater inter-individual variability (Figure 1, fourth row). In summer, RBC 1/2-life was shortest for cubs in the driest year (2013), but with no clear effects in the other two years. In autumn, high RBC 1/2-life variation precluded any clear associations from being detected.

Adults showed no clear pattern with seasonal weather, although prime aged adults had higher RBC 1/2-life variability than old individuals.

Analysis of winter weather COE on OS and antioxidant defences in the following spring

There was substantial potential for COE during our study period: we observed variation in the number of winter frost days, from 50 in 2013 to just 5 in 2014 (2012 equaled the long-term average of 26) and winter rainfall in 2014 was twice the long-term average (other years had normal winter rainfall). All biomarker responses, below, refer to Figure 2 and Table 5.

\section{$\underline{\text { Total antioxidant capacity - AOX }}$}

Winter PCrain and winter PCtemp had significant effects on badger AOX responses in the following spring, with 95\% CIs not overlapping zero. The negative loadings on PCtemp and 
PCrain indicate that warmer, frost free and drier weather conditions over the winter were associated with higher spring AOX and greater capacity to mitigate ROS.

$\underline{\text { Peroxidase - antioxidant enzymes }}$

307 Only winter PCrain had a significant effect on PER, with 95\% CIs not overlapping zero, with wetter winters associated with higher spring PER and thus greater capacity to cope with ROS.

Oxidative damage - lipid peroxidation

310 Only winter PCtemp had a significant explanatory relationship with LP, with 95\% CIs not 311 overlapping zero, with milder winters associated with higher oxidative damage.

\section{$\underline{\text { Resistance to oxidative stress }- \text { RBC } 1 / 2 \text {-life }}$}

Only PCtemp had a significant effect on RBC resistance to OS, with 95\% CIs not overlapping zero, with longer spring RBC 1/2-life following warmer winter weather.

\section{Climate change projections}

317 Although there were differences in predicted responses between the high and low emissions scenarios, projected climate change scenarios through the $21^{\text {st }}$ Century appeared likely to drive changes in badgers' oxidative stress and antioxidant capacity. From our predictive models, we found that the generally warmer conditions predicted under both scenarios could

321 promote substantial increases in lipid peroxidation in badgers (Figure 3d-f). Despite the

322 potential increase in oxidative damage however, badger antioxidant coping capacity may also increase, as evidenced by the trends for greater AOX (Figure 3a-c) and longer RBC $1 / 2-$ life

324 (Figure 3j-1), though with multi-directional responses in peroxidase concentrations (Figure 
responses fell within the range of values quantified in the present study, albeit with different distributions. This suggests that these responses are physiologically possible.

\section{Discussion}

In support of our primary prediction, we identified a range of associations between weather conditions likely to stress wild badger biology and biomarkers of OS, OD and AOX. Notably, the values for LP (indicating OD) that we observed ( $2.33 \mu \mathrm{M}$; SD 0.87 for males; $2.33 \mu \mathrm{M}$; SD 0.76 for females) were higher than typical values for domestic dogs $(1.70 \mu \mathrm{M}$ for male; $1.5 \mu \mathrm{M}$ for females: Todorova et al. 2005), as a lab animal analogue. This is congruent with expectations that wild-living animals will experience higher oxidative stress than domestic animals. We also emphasize that we used metrics of both enzymatic and non-enzymatic antioxidant capacity here, where many previous studies have focused solely on antioxidant defences, erroneously assuming that this will indicate levels of OS. Absolute antioxidant levels are, in fact, only informative if the levels of ROS or OD are also known (see Monaghan et al. 2009). individuals in good or bad body condition (BCI) showed different levels of OD or antioxidant defences (but see Montes et al. 2011). This suggests that any OS / OD arising was not due to weather-related effects of food supply, expenditure and starvation per se, but likely due to repeated short-term cycles of weight / loss gain, where cubs are known to have a lower tolerance for enduring and remediating periods of food scarcity (Newman et al. 2011; Macdonald and Johnson 2015). Sex also had no distinct effect on OS biomarkers, implying that the different life-history stressors affecting males and females caused similar levels of OS / OD. 

ensuing spring trapping, where our study coincided with critical variation in winter precipitation in the mild year (2014; Table 2). Drier and milder winter conditions were associated with higher LP, but also with longer RBC 1/2-life and higher AOX in the following spring. In the UK, badgers do not truly hibernate (i.e., conserve protein catabolism, see Newman et al. 2011), but undergo varying extents of torpor, dropping their activity levels and basal metabolic rate with colder winter conditions (Noonan et al. 2014; McClune et al. 2015). Exercise induces OS (Alessio 1993; Radak et al. 2008), conversely reduced activity and metabolic rate during torpor tends to lessen the risk of oxidative damage (Heldmaier and Ruf 1992). Reinforcing this proposition, wetter, less frosty winters (promoting earthworm availability) were associated with higher PER - plausibly linked to ROS generated by the metabolic cost of warmer conditions promoting higher activity rates (Noonan et al. 2014) at a time of year when thermoregulation (De Quiroga 1992) is expensive and food is scarce.

Our forth prediction, that badger cubs would be more susceptible to OS than adults, was largely supported. This was especially so when they were very young in the spring, when cubs were more prone to OD and suffered greater LP than adults; although both cubs and adults had similar RBC 1/2-life. Due to the scaling of metabolic rate to mass (McClune et al. 2015), cubs, initially in the $1.7-3.0 \mathrm{~kg}$ range in early spring (vs adults ranging $7-9 \mathrm{~kg}$; Macdonald et al. 2015), would be expected to generate proportionately more ROS than adults. Badger cubs grow rapidly in the spring and faster juvenile growth-rate can confer an early survival advantage in badgers (Newman et al. 2001) and generally (Taborsky 2006; Dmitriew 2011). Growth rate and growth hormones are generally linked to higher ROS production, via metabolic activity (Holzenberger et al. 2003), potentially exacerbating OD, as seen in birds (e.g., Alonso-Alvarez et al. 2007; Kim et al. 2011). 
Nevertheless, cubs concurrently also exhibited generally lower AOX than adults except in 2013, which was particularly cool and dry, when they matched adults. Potentially badger cubs can only attempt to mitigate the ROS generated by growth when rainfall is not too extreme - although they still fail to do so effectively because LP was consistently high under these weather conditions. PER was similar between age-classes, except in the spring of 2012, when cubs had lower PER than adults. Cub RBC 1/2-life was shortest with the abnormally dry conditions of 2013. Drought impacts badger foraging success (Macdonald and Newman 2002) and exacerbates the morbidity caused by pandemic coccidiosis in badger cubs (Newman et al. 2001) - potentially further exacerbating OS.

Higher cub LP actually arose with intermediate rainfall and warmer temperatures, but higher rainfall resulted in more inter-individual variation. Similarly, wetter spring conditions were associated with longer cub RBC 1/2-life, i.e., less OD; although longer adult RBC 1/2-life was associated with warmer conditions and intermediate rainfall, more congruent with weather effects on adult survival rate. High mean badger cub OS was also linked to greater inter-individual variation, although variability decreased as seasons progressed within each year, possibly due to selective mortality of mal-adapted individuals (Penteriani et al. 2009; Gaillard and Yoccoz, 2003).

Interestingly, however, and contrary to our initial position, weather effects on OS / OD biomarkers largely did not correspond with the negative quadratic weather effects on cub mortality that Nouvellet et al. (2013) found in a more extensive and purely actuarial study of this same population. Conforming with our fifth prediction, however, adult biomarkers were more in accord with adult survival dynamics, with wetter (and slightly cooler) conditions associated with higher AOX and PER, indicative of a greater ability to resist OS. This implies that any mechanistic relationship between drivers of OS /OD and absolute mortality outcomes in badgers is also influenced by other co-factors, at least for cubs. 

in milder years, when higher numbers of cubs survived until the spring trapping (2012 and especially 2014), there was considerable inter-individual variation in OS measurements, but along a continuum rather than according to distinct phenotypes - refuting prediction seven. This suggests that individuals may follow trade-off strategies, investing differentially in mitigating OS /OD versus other developmental traits, which might have a selective advantage only under stressful weather conditions (Metcalfe and Alonso-Alvarez 2010; Bilham et al. 2013). For instance, in this same badger population Annavi et al. (2014) found advantages of paternal heterozygosity on cub survival rates only in years with benign weather; in harsh years all individuals were similarly prone to mortality, irrespective of subtle genetic advantages.

\section{Conclusions}

414 Identifying that distinct OS, OD and AOX biomarker responses were associated with 415 prevailing and carry-over weather conditions, led us to consider how these biomarkers might 416 be affected by climate change projections for the UK (Murphy et al. 2009). While our models 417 suggest future conditions could lead to substantial increases in lipid peroxidation, badgers may well have the adaptability to cope with warmer conditions because simultaneously their

419 antioxidant coping capacity was also predicted to increase. Indeed, this would be congruent 420 with the European badgers' wide bioclimatic niche, spread from the Mediterranean to the 421 Arctic (Johnson et al. 2002). 
423

424

425 mammals at any given location will be unable to respond to climate change adequately and in some regions up to $39 \%$ may be unable to keep pace. Berteaux et al. (2006) identify a lack of understanding on proximate causality as one of the main constraints when projecting the effects of climate change on mammals. Therefore, identifying mechanistic eco-physiological associations with climate change is broadly relevant (e.g., Helmuth et al. 2005), beyond badgers and may well provide an additional tool with which to assess climate change vulnerabilities.

\section{Author Contributions Statement}

$\mathrm{KB}$ and $\mathrm{CN}$ conceived the ideas; $\mathrm{KB}, \mathrm{CN}, \mathrm{MN}$ and $\mathrm{CDB}$ collected the samples, DWM directed the badger fieldwork; $\mathrm{KB}$ and $\mathrm{AB}$ analysed the samples, with ALS overseeing the lab work; KB and MN analysed the data; $\mathrm{CN}, \mathrm{KB}, \mathrm{CDB}$ and DWM led the writing of the manuscript. All authors contributed to the manuscript writing.

\section{Data Accessibility}

Data summaries included in the manuscript and appendices are comprehensive; however, all data will be archived in Dryad upon acceptance.

\section{References}

Alessio H.M. 1993. Exercise-induced oxidative stress. Med Sci Sports Exerc 25:218-224. 
Allen, M. R., Barros, V. R., Broome, J., Cramer, W., Christ, R., Church, J. A., ... \& Edenhofer, O. (2014). IPCC fifth assessment synthesis report-climate change 2014 synthesis report.

Alonso-Alvarez C., S. Bertrand, B. Faivre B. and G. Sorci. 2007. Increased susceptibility to oxidative damage as a cost of accelerated somatic growth in zebra finches. Funct Ecol 21:873-879.

Anderson, D.R. 2008. Model Based Inference in the Life Sciences: A Primer on Evidence. Springer New York, New York, NY.

Annavi G., C. Newman, C.D. Buesching, D.W. Macdonald, T. Burke, and H.L. Dugdale. 2014. Heterozygosity-fitness correlations in a wild mammal population: accounting for parental and environmental effects. Ecol Evol 4:2594-2609.

Bartoń K. 2016. MuMIn: Multi-Model Inference. R package version 1.15.6. https://CRAN.Rproject.org/package=MuMIn

Beaulieu M., A.-M. Thierry, D. González-Acuña, and M.J. Polito. 2013. Integrating oxidative ecology into conservation physiology. Cons Physiol 1:cot004.

Berteaux D., M. Humphries, C. Krebs, M. Lima, A. McAdam, N. Pettorelli, D. Réale, T. Saitoh, E. Tkadlec, and R.B.Weladji. 2006. Constraints to projecting the effects of climate change on mammals. Clim Res 32:151-158.

Bilham K., Y.-W. Sin, C. Newman, C.D. Buesching, and D.W.Macdonald. 2013. An example of life history antecedence in the European badger (Meles meles): rapid development of juvenile antioxidant capacity, from plasma vitamin E analogue. Ethol Ecol Evol 25:330-350.

Burnham K.P., D.R. Anderson, K.P. Huyvaert. 2011. AIC model selection and multimodel 
inference in behavioral ecology: some background, observations, and comparisons. Beh Ecol Sociobiol 65:23-35.

469

470

471

472

473

474

475

476

477

Costantini D., M. Rowe, M.W. Butler, and K.J. McGraw. 2010. From molecules to living systems: historical and contemporary issues in oxidative stress and antioxidant ecology. Funct Ecol 24:950-959.

Curry J.P. 2004. Factors affecting the abundance of earthworms in soils. Pp 91-113 in C.A. Edwards, ed. Earthworm ecology.CRC Press (Taylor and Francis Group), New York, USA.

Dmitriew C.M. 2011. The evolution of growth trajectories: what limits growth rate? Biol Rev $86: 97-116$

De Quiroga G.B. 1992. Brown fat thermogenesis and exercise: two examples of physiological oxidative stress? Free Radic Biol Med 13:325-340.

Domingo-Roura X., C. Newman, F. Calafel, and D.W. Macdonald. 2001. Blood biochemistry reflects seasonal nutritional and reproductive constraints in the Eurasian badger (Meles meles). Physiol Biochem Zool 74:450-460.

Eisler H., K.-U.Fröhlich, and E. Heidenreich. 2004. Starvation for an essential amino acid induces apoptosis and oxidative stress in yeast. Exp Cell Res. 300:345-353.

Finn P.F. and J.F. Dice. 2006. Proteolytic and lipolytic responses to starvation. J. Nutr 22:830-844.

Gaillard J.-M. and N.G. Yoccoz. (2003) Temporal variation in survival of mammals: a case of environmental canalization? Ecology 84:3294-3306.

Harrison X. A., J. D. Blount, R. Inger, D.R. Norris, and S. Bearhop. 2011. Carry-over effects as drivers of fitness differences in animals. J Anim Ecol 80:4-18. 
Heldmaier G. and T. Ruf. 1992. Body temperature and metabolic rate during natural hypothermia in endotherms. J Comp Physiol B 162:696-706.

Helmuth B., J.G. Kingsolver, and E. Carrington. 2005. Biophysics, physiological ecology, and climate change: does mechanism matter? Annu Rev Physiol 67:177-201.

Holzenberger M.J. Dupont, B. Ducos, P. Leneuve, A. Géloën, P.C. Even, P. Cervera, and Y. Le Bouc. 2003. IGF-1 receptor regulates lifespan and resistance to oxidative stress in mice. Nature 42:182-187.

Johnson D.D.P., W. Jetz, and D.W. Macdonald. 2002. Environmental correlates of badger social spacing across Europe. J Biogeog 29:411-425.

Kim S. Y., J. C. Noguera, J. Morales, and A. Velando. 2011. Quantitative genetic evidence for trade-off between growth and resistance to oxidative stress in a wild bird. Evol Ecol 25:61-472.

Kronfeld-Schor N. and T. Dayan. 2013. Thermal ecology, environments, communities, and global change: energy intake and expenditure in endotherms. Annu Rev Ecol, Evol S 44:461-480.

Kurata M., M. Suzuki, and N. S. Agar. 1993.. Antioxidant systems and erythrocyte life-span in mammals. Comp Biochem Phys B 106:477-487.

Leeuwenburgh C. and J.W. Heinecke. 2001. Oxidative stress and antioxidants in exercise. Curr Med Chem 8:829-838.

Macdonald D.W. and C. Newman. 2002. Population dynamics of badgers (Meles meles) in Oxfordshire, UK: numbers, density and cohort life histories, and a possible role of climate change in population growth. J Zool 256:121-138. 
Macdonald, D.W., C. Newman, C., and C.D. Buesching. 2015. Badgers in the rural landscape - conservation paragon or farmland pariah? Lessons from the Wytham Badger Project. Pp 65-95 in D. W. Macdonald and R. E. Feber, eds. Wildlife Conservation on Farmland Volume 2: Conflict in the Coutryside. Oxford University Press, Oxford.

Macdonald D.W., C. Newman, C.D. Buesching, and P. Nouvellet. 2010. Are badgers 'Under The Weather'? Direct and indirect impacts of climate variation on European badger (Meles meles) population dynamics. Glob Change Biol, 16:2913-2922.

Macdonald D.W. and D.D.P. Johnson (2015) Patchwork planet: the resource dispersion hypothesis, society, and the ecology of life. J Zool 295:75-107.

McClune D.W., B. Kostka, R. J. Delahay, W.I. Montgomery, N.J. Marks, and D.M. Scantlebury. 2015. Winter Is Coming: Seasonal Variation in Resting Metabolic Rate of the European Badger (Meles meles). Plos One 10.e0135920.

Metcalfe N.B. and C.Alonso-Alvarez. 2010. Oxidative stress as a life-history constraint: the role of reactive oxygen species in shaping phenotypes from conception to death. Funct Ecol 24:984-996.

Monaghan P., N.B. Metcalfe, and R. Torres. 2009. Oxidative stress as a mediator of life history trade-offs: mechanisms, measurements and interpretation. Ecol Lett 12:75-92.

Montes I., C. Newman, R. Mian, and D.W. Macdonald. 2011. Radical health: ecological corollaries of body condition, transport stress and season on plasma antioxidant capacity in the European badger. J Zool 284:14-123.

Morales A.E., A. Perez-Jimenez, M.C. Hidalgo, E. Abellán, and G. Cardenete. 2004. Oxidative stress and antioxidant defenses after prolonged starvation in Dentex dentex liver. Comp Biochem Physiol C 139:153-161. 
Moss, R. H., J. A. Edmonds, K. A. Hibbard, M. R. Manning, S. K. Rose, D. P. van Vuuren, et al. 2010. The next generation of scenarios for climate change research and assessment. Nature 463:747-756.

Murphy J.M., D.M.H. Sexton, G.J. Jenkins, et al. 2009. UK Climate Projections Science Report: Climate Change Projections.

Mylonas C. and D. Kouretas. 1998. Lipid peroxidation and tissue damage. In vivo 13:295309.

Nakicenovic, N. J. et al. 2005. Special Report on Emissions Scenarios (eds Nakicenovic, N. \& Swart, R.) IPCC, Cambridge Univ. Press.

Nielsen F., B. B. Mikkelsen, J. B. Nielsen, H. R. Andersen, and P. Grandjean. 1997. Plasma malondialdehyde as biomarker for oxidative stress: reference interval and effects of life-style factors. Clin Chem 43:1209-1214.

Newman C. and D.W. Macdonald. 2015. The Implications of climate change for terrestrial UK Mammals. Terrestrial biodiversity Climate change impacts report card Technical paper. Living with environmental change partnership. NERC.

Newman C., D.W. Macdonald, and M.A. Anwar. 2001. Coccidiosis in the European badger, Meles meles in Wytham Woods: infection and consequences for growth and survival. Parasitology 123:33-142.

Newman C., Y.-B. Zhou, C.D. Buesching, Y. Kaneko, and D.W. Macdonald. 2011. Contrasting sociality in two widespread, generalist, mustelid genera, Meles and Martes. Mamm Study 36:169-188.

Newman, C., C.D. Buesching, and D.W. Macdonald. 2017. Meline Mastery of Meteorological Mayhem: The effects of climate changeability on European badger 

population dynamics. Pp 420-433. In: The Biology and Conservation of Wild Musteloids. D.W. Macdonald, C. Newman \& L. Harrington, Eds. OUP.

Noonan M.J., A. Markham, C. Newman, N. Trigoni, C.D. Buesching, S.A. Ellwood, and D.W.Macdonald. 2014. Climate and the individual: inter-annual variation in the autumnal activity of the European badger (Meles meles). Plos One 9.e83156.

Noonan M. J., M.A. Rahman, C. Newman, C.D. Buesching, and D.W. Macdonald. 2015. Avoiding verisimilitude when modelling ecological responses to climate change: the influence of weather conditions on trapping efficiency in European badgers (Meles meles). Glob Change Biol. 21:3575-3585.

Nouvellet P., C. Newman, C.D. Buesching, and D.W. Macdonald. 2013. A multi-metric approach to investigate the effects of weather conditions on the demographic of a terrestrial mammal, the European badger (Meles meles). Plos One 8.e68116.

Parmesan C., T.L. Root, and M.R. Willig. 2000. Impacts of extreme weather and climate on terrestrial biota. B Am Meteorol Soc 81:443.

Penteriani V., M. Ferrer, F. Otalora, and M. del Mar Delgado. 2009. When individuals senesce: the 'Florida effect'on stable populations of territorial, long-lived birds. Oikos $118: 321-327$

Protection of Badgers Act. 1992. http://www.legislation.gov.uk/ukpga/1992/51/contents

R Core Team. 2016. R: A language and environment for statistical computing. R Foundation for Statistical Computing, Vienna, Austria. https://www.R-project.org/.

Radak Z., H.Y. Chung, E. Koltai, A.W. Taylor, and S. Goto. 2008. Exercise, oxidative stress and hormesis. Ageing Res Rev 7:34-42.

Schloss C.A., T.A. Nuñez, and J.J. Lawler. 2012. Dispersal will limit ability of mammals to 
track climate change in the Western Hemisphere. P Natl A Sci USA 109:8606-8611. doi: 10.1073/pnas.1116791109.

Sexton D., K. Richardson, G. Harris, A. Karmalkar, J. Murphy, S. Brown, and J. Tinker. 2016. Assessment of UKCP09, including comparison against IPCC CMIP5 multimodel simulations. Met Office Hadley Centre Technical Note no. 99, www.metoffice.gov.uk/media/pdf/m/g/CMIP5vUKCP09_Technical_notes.pdf

Sies H. 1997. Oxidative stress: oxidants and antioxidants. Exp Physiol 8:291-295.

Sih A. 2013. Understanding variation in behavioural responses to human-induced rapid environmental change: a conceptual overview. Anim Beh 85:1077-1088.

Smit B., I. Burton, R.J. Klein, and J. Wandel. 2000. An anatomy of adaptation to climate change and variability. Climatic Change 45:223-251.

Sun Q., C. Stevens, C. Newman, C.D. Buesching, and D.W. Macdonald. 2015. Cumulative experience, age-class, sex and season affect the behavioural responses of European badgers (Meles meles) to handling and sedation. Anim Welf 24:373-385.

Taborsky B. 2006. The influence of juvenile and adult environments on life-history trajectories. P R Soc London 273:741-750.

Todorova I., G. Simeonova, D. Kyuchukova, D. Dinev, and V. Gadjeva. 2005. Reference values of oxidative stress parameters (MDA, SOD, CAT) in dogs and cats. Comp Clin Pathol 13:190-194.

Vijayakumar R., D. Surya, and N. Nalini. 2004. Antioxidant efficacy of black pepper (Piper nigrum L.) and piperine in rats with high fat diet induced oxidative stress. Redox Rep 9:105-110. 
604 White P.C. and A.I. Ward. 2011. Interdisciplinary approaches for the management of existing 605 and emerging human-wildlife conflicts. Wild Res 37:623-629.

606 White T. 2008. The role of food, weather and climate in limiting the abundance of animals.

607 Biol Rev 83:227-248.

608 Woodroffe R. 1995. Body condition affects implantation date in the European badger, Meles 609 meles. J Zool 236:183-188.

610

611

612

613 
Table 1 Summary of the individuals sampled in the study. Age was known from year of

615 birth, and individuals were classified as $\mathrm{Cub}<1 \mathrm{yr}$; prime adult 1-5 yrs; old adult $\geq 6$ yrs.

\begin{tabular}{|c|c|c|c|}
\hline Year & Season & Age class & $n$ \\
\hline \multirow[t]{9}{*}{2012} & Spring & $\mathrm{Cub}$ & 31 \\
\hline & & Prime adult & 31 \\
\hline & & Old adult & 25 \\
\hline & Summer & $\mathrm{Cub}$ & 16 \\
\hline & & Prime adult & 37 \\
\hline & & Old adult & 30 \\
\hline & Autumn & $\mathrm{Cub}$ & 14 \\
\hline & & Prime adult & 40 \\
\hline & & Old adult & 29 \\
\hline \multirow[t]{9}{*}{2013} & Spring & $\mathrm{Cub}$ & 23 \\
\hline & & Prime adult & 28 \\
\hline & & Old adult & 21 \\
\hline & Summer & $\mathrm{Cub}$ & 9 \\
\hline & & Prime adult & 30 \\
\hline & & Old adult & 24 \\
\hline & Autumn & $\mathrm{Cub}$ & 2 \\
\hline & & Prime adult & 25 \\
\hline & & Old adult & 19 \\
\hline \multirow[t]{6}{*}{2014} & Spring & $\mathrm{Cub}$ & 34 \\
\hline & & Prime adult & 17 \\
\hline & & Old adult & 19 \\
\hline & Summer & $\mathrm{Cub}$ & 16 \\
\hline & & Prime adult & 24 \\
\hline & & Old adult & 20 \\
\hline
\end{tabular}

616

617 
618 Table 2 Mean weather conditions in Oxford, UK for the three study years. Averages for the 619 last 30 years are also presented.

\begin{tabular}{lcccc}
\hline Rainfall (mm/month) & 30 year mean & $\mathbf{2 0 1 2}$ & $\mathbf{2 0 1 3}$ & $\mathbf{2 0 1 4}$ \\
& & & & \\
\hline Winter & 55.78 & 42.37 & 69.73 & 111.57 \\
Spring & 51.26 & 74.27 & 55.87 & 59.90 \\
Summer & 52.25 & 112.43 & 27.43 & 56.00 \\
Autumn & 62.88 & 88.36 & 60.77 & - \\
& & & & \\
\hline
\end{tabular}

\begin{tabular}{lrrrr}
\hline Min temperature $\left({ }^{\circ} \mathbf{C}\right)$ & & & & \\
\multicolumn{1}{l}{ Winter } & 2.18 & 2.63 & 1.80 & 3.77 \\
Spring & 5.57 & 5.97 & 3.60 & 6.27 \\
Summer & 12.25 & 12.60 & 12.40 & 12.33 \\
Autumn & 7.75 & 6.83 & 7.87 & \\
& & & & \\
\hline
\end{tabular}

Max temperature $\left({ }^{\circ} \mathrm{C}\right)$

\begin{tabular}{lrrrr}
\hline Winter & 7.85 & 8.8 & 7.07 & 9.67 \\
Spring & 13.94 & 14.77 & 11.70 & 14.97 \\
Summer & 21.72 & 20.40 & 22.63 & 22.40 \\
Autumn & 14.88 & 13.97 & 15.07 & - \\
\hline
\end{tabular}

Frost (total days)

$\begin{array}{lllll}\text { Winter } & 26 & 26 & 50 & 5\end{array}$

620

621 
Table 3 Summary statistics of badger (Meles meles) biomarkers in Wytham Woods, UK throughout the study period. Values presented are means \pm standard deviations. Total antioxidant capacity (AOX) was measured as non-enzymatic plasma antioxidant capacity (in $\mu \mathrm{M}$ ) and enzymatic antioxidant capacity via peroxidase (PER; in $\mathrm{mU} / \mathrm{ml}$ ). As biomarkers of OD, lipid peroxidation (LP) was measured as malondialdehyde accumulation in plasma (in $\mu \mathrm{M}$ ) and red blood cell 1/2-life (RBC 1/2-life) was calculated as the time it took $50 \%$ of RBCs to lyse in the presence of an oxidant (in min). For sample sizes see Table 1.

\begin{tabular}{|c|c|c|c|c|c|}
\hline Season & Biomarker & Age class & 2012 & 2013 & 2014 \\
\hline \multirow[t]{12}{*}{ Spring } & $\mathrm{AOX}$ & $\mathrm{Cub}$ & $160.73 \pm 66.02$ & $114.98 \pm 57.60$ & $206.71 \pm 104.02$ \\
\hline & & Prime Adult & $209.2 \pm 69.16$ & $121.83 \pm 42.80$ & $176.72 \pm 82.68$ \\
\hline & & Old Adult & $228.96 \pm 52.05$ & $127.95 \pm 36.11$ & $242.81 \pm 105.12$ \\
\hline & PER & $\mathrm{Cub}$ & $0.45 \pm 0.10$ & $0.29 \pm 0.05$ & $0.22 \pm 0.08$ \\
\hline & & Prime Adult & $0.53 \pm 0.15$ & $0.34 \pm 0.08$ & $0.33 \pm 0.13$ \\
\hline & & Old Adult & $0.51 \pm 0.07$ & $0.33 \pm 0.06$ & $0.29 \pm 0.12$ \\
\hline & LP & $\mathrm{Cub}$ & $18.65 \pm 14.32$ & $12.36 \pm 5.40$ & $59.54 \pm 40.82$ \\
\hline & & Prime Adult & $8.52 \pm 3.55$ & $5.59 \pm 2.70$ & $26.43 \pm 23.30$ \\
\hline & & Old Adult & $8.27 \pm 3.88$ & $5.53 \pm 2.29$ & $41.11 \pm 26.59$ \\
\hline & RBC 1/2-life & $\mathrm{Cub}$ & $71.49 \pm 12.62$ & $61.74 \pm 5.74$ & $69.88 \pm 11.40$ \\
\hline & & Prime Adult & $71.24 \pm 8.86$ & $62.79 \pm 8.89$ & $88.18 \pm 17.82$ \\
\hline & & Old Adult & $66.3 \pm 5.03$ & $60.59 \pm 4.72$ & $72.25 \pm 11.65$ \\
\hline \multirow[t]{12}{*}{ Summer } & $\mathrm{AOX}$ & $\mathrm{Cub}$ & $250.19 \pm 61.41$ & $220.02 \pm 62.45$ & $226.89 \pm 122.70$ \\
\hline & & Prime Adult & $255.26 \pm 62.91$ & $132.27 \pm 84.11$ & $234.58 \pm 68.10$ \\
\hline & & Old Adult & $266.98 \pm 55.39$ & $79.66 \pm 55.06$ & $246.92 \pm 63.79$ \\
\hline & PER & $\mathrm{Cub}$ & $0.29 \pm 0.07$ & $0.48 \pm 0.10$ & $0.4 \pm 0.15$ \\
\hline & & Prime Adult & $0.46 \pm 0.22$ & $0.41 \pm 0.07$ & $0.46 \pm 0.20$ \\
\hline & & Old Adult & $0.71 \pm 0.18$ & $0.39 \pm 0.06$ & $0.35 \pm 0.09$ \\
\hline & LP & $\mathrm{Cub}$ & $7.94 \pm 4.00$ & $9.63 \pm 2.74$ & $14.5 \pm 4.82$ \\
\hline & & Prime Adult & $6.31 \pm 2.14$ & $6.26 \pm 1.35$ & $12.22 \pm 5.02$ \\
\hline & & Old Adult & $4.76 \pm 3.03$ & $6.4 \pm 2.03$ & $11.15 \pm 5.43$ \\
\hline & RBC 1/2-life & $\mathrm{Cub}$ & $65.17 \pm 6.19$ & $58.91 \pm 2.79$ & $64.85 \pm 6.56$ \\
\hline & & Prime Adult & $64.89 \pm 4.41$ & $60.37 \pm 4.64$ & $68.86 \pm 4.97$ \\
\hline & & Old Adult & $65.07 \pm 5.16$ & $62.42 \pm 5.87$ & $68.42 \pm 4.85$ \\
\hline \multirow[t]{12}{*}{ Autumn } & $\mathrm{AOX}$ & $\mathrm{Cub}$ & $169.04 \pm 20.43$ & $495.74 \pm 21.41$ & - \\
\hline & & Prime Adult & $172.79 \pm 23.06$ & $452.9 \pm 158.30$ & - \\
\hline & & Old Adult & $173.01 \pm 27.04$ & $475.16 \pm 183.21$ & - \\
\hline & PER & $\mathrm{Cub}$ & $0.23 \pm 0.03$ & $0.55 \pm 0.14$ & - \\
\hline & & Prime Adult & $0.24 \pm 0.11$ & $0.51 \pm 0.09$ & - \\
\hline & & Old Adult & $0.23 \pm 0.04$ & $0.48 \pm 0.12$ & - \\
\hline & LP & $\mathrm{Cub}$ & $12.7 \pm 5.97$ & $17.09 \pm 9.20$ & - \\
\hline & & Prime Adult & $9.15 \pm 8.77$ & $30.36 \pm 14.52$ & - \\
\hline & & Old Adult & $8.35 \pm 3.10$ & $26.28 \pm 12.88$ & - \\
\hline & RBC 1/2-life & $\mathrm{Cub}$ & $78.92 \pm 10.14$ & $78.21 \pm 20.21$ & - \\
\hline & & Prime Adult & $74.69 \pm 5.42$ & $68.87 \pm 8.67$ & - \\
\hline & & Old Adult & $73.6 \pm 6.95$ & $68.4 \pm 9.40$ & - \\
\hline
\end{tabular}


629 Table 4 Model averaging for the variables predictive of variation in badger (Meles meles) biomarkers in Wytham Woods, UK. The model630 averaged estimates $(\theta), 95 \%$ confidence intervals $(\mathrm{CI})$, and relative influence $(\mathrm{RI})$ of each parameter are presented. Biomarkers include total 631 antioxidant capacity (AOX), measured as non-enzymatic plasma antioxidant capacity (in $\mu \mathrm{M}$ ); enzymatic antioxidant capacity, measured as 632 peroxidase concentration (PER; in $\mathrm{mU} / \mathrm{ml}$ ); lipid peroxidation (LP), measured as malondialdehyde accumulation in plasma (in $\mu \mathrm{M}$ ) and red 633 blood cell $1 / 2$-life (RBC $1 / 2$-life), calculated as the time it took $50 \%$ of RBCs to lyze in the presence of an oxidant (in min). Asterisks denote 634 coefficient estimates that differed significantly from zero (based on $95 \%$ confidence intervals).

\begin{tabular}{|c|c|c|c|c|c|c|c|c|c|c|c|c|c|c|c|c|c|}
\hline & & & AOX & & & & $\overline{L P}$ & & & & PER & & & & & C 1/2 life & \\
\hline & Category level & $\mathbf{R I}$ & $\boldsymbol{\theta}$ & $\begin{array}{c}\text { Lower } \\
95 \% \text { CI }\end{array}$ & $\begin{array}{c}\text { Upper } \\
95 \% \text { CI }\end{array}$ & $\mathbf{R I}$ & $\boldsymbol{\theta}$ & $\begin{array}{c}\text { Lower } \\
95 \% \text { CI }\end{array}$ & $\begin{array}{c}\text { Upper } \\
\mathbf{9 5} \% \text { CI }\end{array}$ & $\mathbf{R I}$ & $\boldsymbol{\theta}$ & $\begin{array}{c}\text { Lower } \\
95 \% \text { CI }\end{array}$ & $\begin{array}{c}\text { Upper } \\
95 \% \text { CI }\end{array}$ & RI & $\boldsymbol{\theta}$ & $\begin{array}{c}\text { Lower } \\
95 \% \text { CI }\end{array}$ & $\begin{array}{c}\text { Upper } \\
\mathbf{9 5 \%} \text { CI }\end{array}$ \\
\hline Intercept & - & & $266.80^{*}$ & 197.28 & 336.40 & & 4.08 & 3.76 & 4.40 & & 0.33 & 0.23 & 0.42 & & $72.67 *$ & 65.42 & 79.92 \\
\hline \multirow[t]{3}{*}{ Age class } & $\mathrm{Cub}$ & 0.93 & - & - & - & 1.00 & - & - & - & 1.00 & - & - & - & 1.00 & - & - & - \\
\hline & Prime & & -14.94 & -107.21 & 77.34 & & $-0.44^{*}$ & -0.71 & -1.56 & & $0.15^{*}$ & 0.03 & 0.27 & & $21.25^{*}$ & 11.70 & 30.80 \\
\hline & Old & & 67.18 & -25.83 & 160.20 & & $-0.53^{*}$ & -0.80 & -2.72 & & 0.10 & -0.01 & 0.22 & & 0.18 & -9.43 & 9.78 \\
\hline BCI & - & 1.00 & -8.48 & -2.55 & 237.97 & 0.43 & 0.10 & -1.05 & 1.25 & 0.32 & -0.09 & $\begin{array}{c}-0.43 \\
\end{array}$ & 0.25 & 0.97 & 18.73 & -7.36 & 44.81 \\
\hline PCrain & - & 0.99 & -72.45 & -147.05 & 4.156 & 1.00 & $-1.39 *$ & -1.69 & -1.10 & 1.00 & $0.32 *$ & 0.23 & 0.40 & 1.00 & 6.78 & -1.12 & 14.67 \\
\hline PCtemp & - & 1.00 & $101.80^{*}$ & 4.89 & 154.69 & 1.00 & $1.46^{*}$ & 1.24 & 1.69 & 0.99 & $-0.10^{*}$ & -0.17 & \begin{tabular}{c|}
-0.03 \\
\end{tabular} & 1.00 & 5.32 & -0.12 & 10.77 \\
\hline \multirow[t]{3}{*}{ Season } & Spring & 1.00 & - & - & - & 1.00 & - & - & - & 1.00 & - & - & - & 1.00 & - & - & - \\
\hline & Summer & & -87.67 & -1.59 & 1419.24 & & $-18.79 *$ & -23.11 & -14.47 & & 0.70 & -0.49 & 1.88 & & -116.20 & -271.92 & 39.05 \\
\hline & Autumn & & $190.70^{*}$ & 1.05 & 276.81 & & -0.04 & -0.44 & 0.35 & & 0.09 & -0.04 & 0.22 & & 3.54 & -5.35 & 12.43 \\
\hline \multirow[t]{2}{*}{ Sex } & Female & 1.00 & - & - & - & 0.09 & - & - & - & 0.01 & - & - & - & 0.46 & - & - & - \\
\hline & Male & & -8.54 & -21.32 & 6.15 & & -0.01 & -0.05 & 0.04 & & $>-0.01$ & $>-0.01$ & $<0.01$ & & 0.282 & -0.95 & 1.46 \\
\hline \multirow[t]{3}{*}{ Age class*PCrain } & Cub*PCrain & 1.00 & - & - & - & 0.03 & - & - & - & 0.17 & - & - & - & 1.00 & - & - & - \\
\hline & Prime*PCrain & & $170.30^{*}$ & 54.31 & 286.36 & & $<0.01$ & -0.05 & 0.05 & & 0.01 & -0.04 & 0.06 & & $-29.99 *$ & -41.94 & -18.04 \\
\hline & Old*PCrain & & 65.45 & -49.53 & 180.43 & & $>-0.01$ & -0.06 & 0.06 & & 0.02 & -0.09 & 0.13 & & $-16.11^{*}$ & -27.83 & -4.29 \\
\hline \multirow[t]{2}{*}{ Age class*PCtemp } & Cub*PCtemp & 1.00 & - & - & - & 0.07 & - & - & - & 0.85 & - & - & - & 1.00 & - & - & - \\
\hline & Prime*PCtemp & & -71.04 & -151.27 & 9.19 & & 0.01 & -0.10 & 0.12 & & 0.04 & -0.04 & 0.12 & & $21.85^{*}$ & 13.60 & 30.11 \\
\hline
\end{tabular}




\begin{tabular}{|c|c|c|c|c|c|c|c|c|c|c|c|c|c|c|c|c|c|}
\hline & Old*PCtemp & & 6.56 & -74.69 & 87.80 & & 0.02 & -0.14 & 0.17 & & 0.03 & -0.05 & 0.11 & & 7.23 & -1.12 & 15.56 \\
\hline \multirow[t]{6}{*}{ Age class*Season } & Cub/Spring & 1.00 & - & - & - & 0.17 & - & - & - & 0.97 & - & - & - & 1.00 & - & - & - \\
\hline & Prime*summer & & -1520.00 & $\begin{array}{c}- \\
3388.72\end{array}$ & 348.10 & & 0.06 & -0.49 & 0.60 & & 0.43 & -0.13 & 0.99 & & -109.40 & -301.73 & 83.023 \\
\hline & Old*Summer & & $-2749.00^{*}$ & 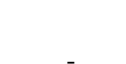 & -838.51 & & 0.01 & -0.63 & 0.65 & & $1.49^{*}$ & 0.20 & 2.79 & & -37.50 & -233.82 & 158.83 \\
\hline & Prime*Autumn & & -52.78 & 4658.70 & 41.47 & & 0.10 & -0.45 & 0.66 & & -0.23 & -0.57 & 0.10 & & $-18.11^{*}$ & -27.92 & -8.30 \\
\hline & Old*Autumn & & -80.53 & -147.02 & 14.98 & & 0.09 & -0.40 & 0.57 & & -0.26 & -0.56 & 0.11 & & -5.68 & -15.58 & 4.19 \\
\hline & & & & -176.04 & & & & & & & & & & & & & \\
\hline \multirow[t]{3}{*}{ PCrain*Season } & Spring/PCrain & 1.00 & - & - & - & 1.00 & - & - & - & 1.00 & - & - & - & 1.00 & - & - & - \\
\hline & Summer*PCrain & & 85.33 & -79.30 & 249.96 & & $2.89^{*}$ & 2.39 & 3.40 & & $-0.43^{*}$ & -0.56 & -0.30 & & 4.46 & -12.52 & 21.45 \\
\hline & Autumn*PCrain & & $-186.4^{*}$ & -328.62 & -44.08 & & $1.04^{*}$ & 0.61 & 1.47 & & $-0.67 *$ & -0.84 & -0.50 & & -2.36 & -17.00 & 12.26 \\
\hline \multirow[t]{3}{*}{ PCtemp*Season } & Spring/PCtemp & 1.00 & - & - & - & 1.00 & - & - & - & 0.97 & - & - & - & 1.00 & - & - & - \\
\hline & Summer*PCtemp & & -67.28 & -942.82 & 808.25 & & $8.44^{*}$ & 5.93 & 10.95 & & -0.26 & -0.96 & 0.44 & & 54.05 & -37.09 & 144.17 \\
\hline & Autumn*PCtemp & & 0.00 & -0.036 & 0.04 & & $<0.01$ & $>-0.01$ & $<0.01$ & & $<0.01$ & $>-0.01$ & $<0.01$ & & $<0.01$ & $>-0.01$ & $<0.01$ \\
\hline \multirow[t]{5}{*}{ Age class* PCrain*Season } & Cub/Spring/PCrain & 1.00 & - & - & - & $<$ & - & - & - & $<0.01$ & - & - & - & 1.00 & - & - & - \\
\hline & Prime*Summer*PCrain & & 2.86 & -210.27 & 215.98 & & $<0.01$ & -0.03 & 0.03 & & $<0.01$ & -0.01 & 0.01 & & $37.40^{*}$ & 15.42 & 59.38 \\
\hline & Old*Summer*PCrain & & $227.00 *$ & 10.51 & 443.59 & & $<0.01$ & -0.05 & 0.05 & & $<0.01$ & -0.01 & 0.01 & & 18.45 & -3.83 & 40.74 \\
\hline & Prime*Autumn*PCrain & & -161.5 & -345.22 & 22.21 & & $<0.01$ & -0.03 & 0.03 & & $<0.01$ & -0.01 & 0.01 & & $42.66^{*}$ & 23.69 & 61.63 \\
\hline & Old*Autumn*PCrain & & -33.86 & -217.53 & 149.80 & & $<0.01$ & -0.03 & 0.03 & & $<0.01$ & -0.01 & 0.01 & & $22.27 *$ & 3.40 & 41.14 \\
\hline \multirow[t]{5}{*}{ Age class* PCtemp*Season } & Cub/Spring/PCtemp & 1.00 & - & - & - & 0.02 & - & - & - & 0.85 & - & - & - & 1.00 & - & - & - \\
\hline & Prime*Summer*PCtemp & & 951.80 & -135.63 & 2039.27 & & -0.01 & -0.29 & 0.27 & & -0.35 & -0.73 & 0.03 & & 29.63 & -82.26 & 141.52 \\
\hline & Old*Summer*PCtemp & & $1536.00^{*}$ & 423.64 & 2648.38 & & $>-0.01$ & -0.34 & 0.33 & & $-0.89^{*}$ & -1.67 & -0.11 & & 15.00 & -99.26 & 129.27 \\
\hline & Prime*Autumn*PCtemp & & 0.01 & -4.31 & 4.33 & & 0.02 & -0.37 & 0.41 & & -0.15 & -0.54 & 0.23 & & -0.02 & -2.26 & 2.22 \\
\hline & Old*Autumn*PCtemp & & 0.01 & -3.88 & 3.89 & & 0.02 & -0.34 & 0.38 & & -0.16 & -0.56 & 0.23 & & -0.01 & -1.50 & 1.48 \\
\hline
\end{tabular}


Table 5 Model averaging for the variables predictive of carry-over-effects in badger (Meles meles) biomarkers in Wytham Woods, UK. The model-averaged estimates $(\theta), 95 \%$ confidence intervals $(\mathrm{CI})$, and relative influence (RI) of each parameter are presented. Biomarkers include total antioxidant capacity (AOX), measured as non-enzymatic plasma antioxidant capacity (in $\mu \mathrm{M}$ ); enzymatic antioxidant capacity, measured as peroxidase concentration (PER; in $\mathrm{mU} / \mathrm{ml}$ ); lipid peroxidation (LP), measured as malondialdehyde accumulation in plasma (in $\mu \mathrm{M}$ ) and red blood cell $1 / 2$-life (RBC $1 / 2$-life), calculated as the time it took $50 \%$ of RBCs to lyze in the presence of an oxidant (in min). Asterisks denote coefficient estimates that differed significantly from zero (based on $95 \%$ confidence intervals)

\begin{tabular}{|c|c|c|c|c|c|c|c|c|c|c|c|c|c|c|c|c|}
\hline & & & AOX & & & & $\mathbf{L P}$ & & & & PER & & & & BC $1 / 2$ life & \\
\hline & RI & $\boldsymbol{\theta}$ & $\begin{array}{l}\text { Lower } \\
95 \% \mathrm{CI}\end{array}$ & $\begin{array}{c}\text { Upper } \\
95 \% \text { CI }\end{array}$ & RI & $\theta$ & $\begin{array}{l}\text { Lower } \\
95 \% \mathrm{CI}\end{array}$ & $\begin{array}{c}\text { Upper } \\
95 \% \text { CI }\end{array}$ & RI & $\bar{\theta}$ & $\begin{array}{l}\text { Lower } \\
95 \% \text { CI }\end{array}$ & $\begin{array}{c}\text { Upper } \\
95 \% \text { CI }\end{array}$ & RI & $\boldsymbol{\theta}$ & $\begin{array}{l}\text { Lower } \\
95 \% \text { CI }\end{array}$ & $\begin{array}{c}\text { Upper } \\
95 \% \text { CI }\end{array}$ \\
\hline Intercept & & 214.68 & 41.36 & 387.99 & & 0.61 & 1.21 & 3.61 & & 0.08 & 0.26 & 0.59 & & $63.88^{*}$ & 35.42 & 92.34 \\
\hline BCI & 1.00 & -68.62 & -639.50 & 502.26 & 0.68 & 1.99 & -4.53 & 3.35 & 0.30 & 0.26 & -0.60 & 0.44 & 0.98 & 13.40 & -78.38 & 105.17 \\
\hline PCrain & 1.00 & 38.38 & 25.44 & 51.31 & 0.77 & 0.08 & -0.27 & 0.03 & 1.00 & 0.01 & 0.09 & 0.13 & 0.44 & -0.14 & -1.40 & 1.12 \\
\hline PCtemp & 1.00 & -20.00 & -26.67 & -13.34 & 1.00 & 0.03 & -0.42 & -0.33 & 0.01 & $<0.01$ & 0.01 & $<0.01$ & 1.00 & $-3.77 *$ & -4.83 & -2.71 \\
\hline Sex - Male & 0.95 & -13.49 & -38.43 & 11.45 & 0.27 & 0.01 & -0.25 & 0.15 & 0.07 & 0.01 & -0.02 & 0.02 & 0.66 & 0.80 & -2.77 & 4.37 \\
\hline
\end{tabular}


Figure 1. Scatter-plots depicting the relationships between biomarkers measured in badgers (Meles meles) in Wytham Woods, UK and weather variables across all age categories. The left-hand panels depict the biomarkers as a function of seasonal mean weather metrics in the reduced dimension space of PCrain; in the right-hand panels weather metrics are reduced according to the dimension space of PCtemp. Cubs $<1$ yr; prime adults $1-5 \mathrm{yr}$; old adults $\geq 6$.

Figure 2. Scatter-plots depicting the carry-over effect (COE) relationships between biomarkers measured in badgers (Meles meles) in Wytham Woods, UK in the spring and the previous winter's weather variables. X-axis depicts extent PCrain and PCtemp axis loadings. All animals here are classed as adult.

Figure 3 Density estimates of projected responses of badger (Meles meles) biomarkers in Wytham Woods, UK to future climate projections under a low (IPCC SRES B1), and high emissions scenario (IPCC SRES A1F1) in relation to the present distributions. The top row (panels a; d; g; and

j) depicts spring responses, the middle row (panels b; e; h; and k) summer responses; and the bottom row (panels c; f; I; and l) autumn responses. We note that although the negative Red blood cell (RBC) half-lives in panel k) are clearly impossible, these were included to depict the substantial negative trend in this biomarker predicted under the high emissions scenario. 
Figure 1
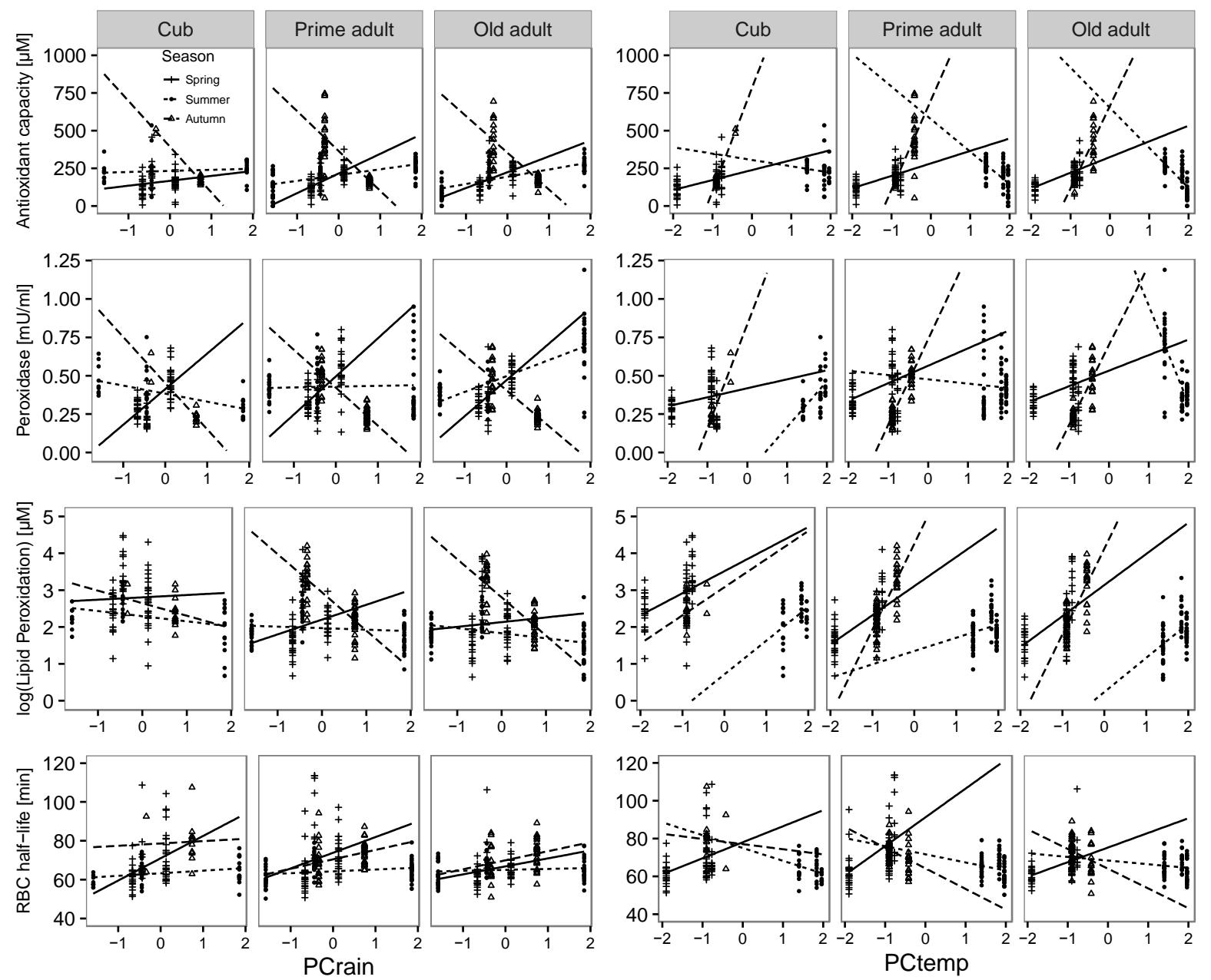

Figure 2
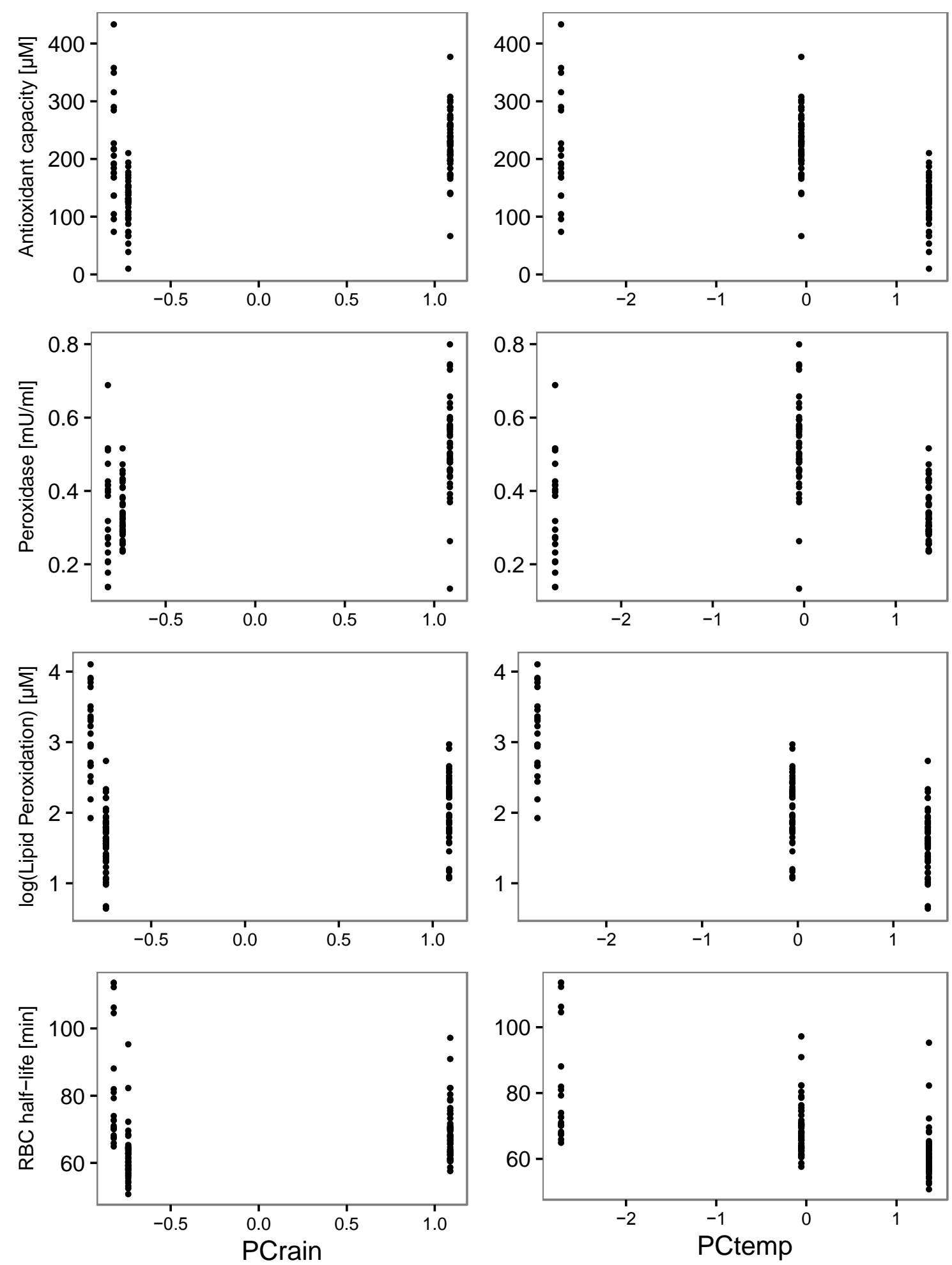

Figure 3
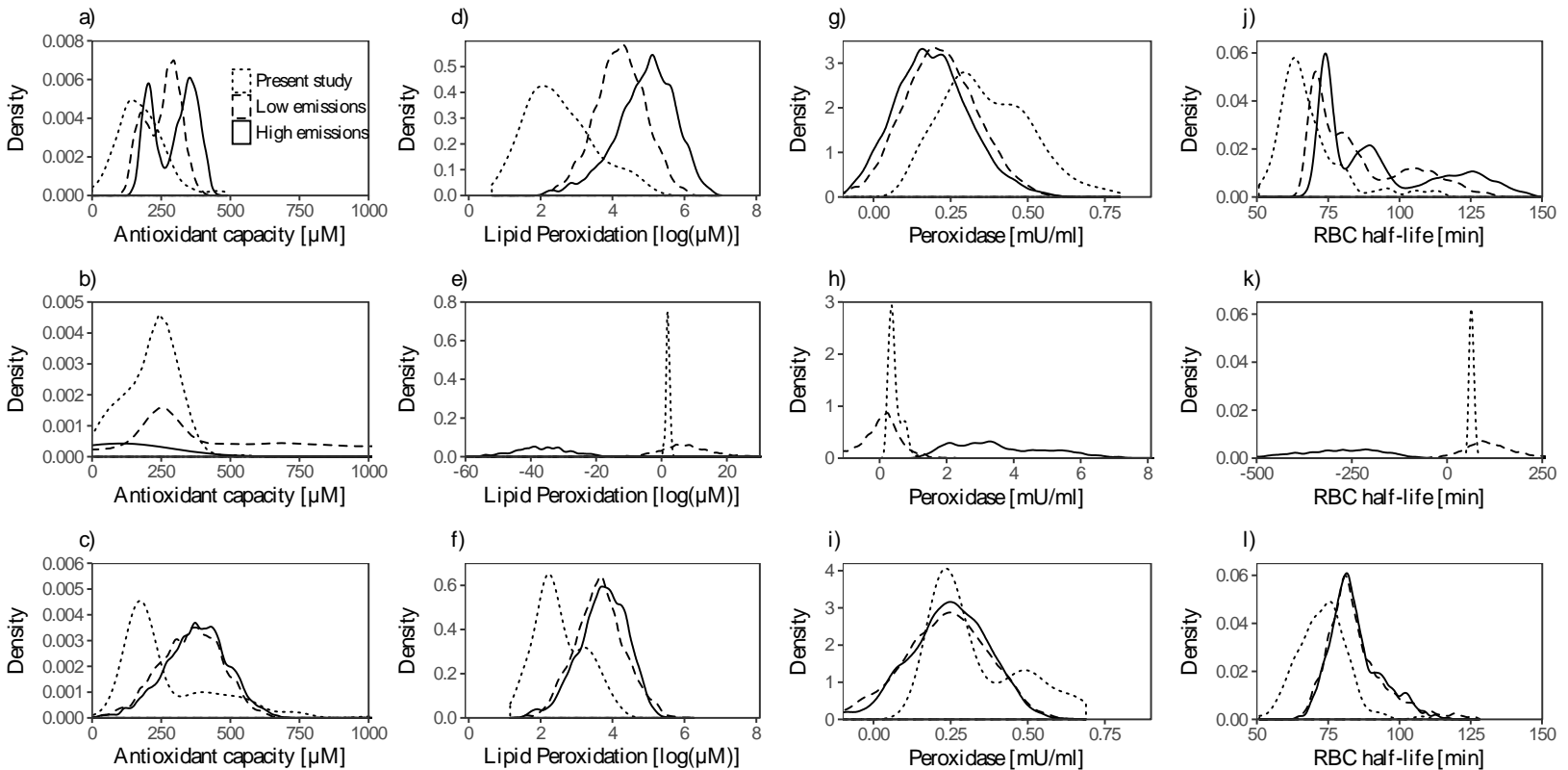


\section{$5 \quad$ Blood sampling}

6 Blood samples were collected from spring 2012 until August 2014, between 8.30 and 11 am, to

7 minimise circadian variations. Individuals were marked with a temporary livestock marker dye to

8 identify recaptures within trapping sessions and thus avoid unnecessary re-sampling.

9 For oxidative stress assays, approximately $12 \mathrm{ml}$ of blood (never more than $5 \%$ estimated badger

10 blood volume by weight) were collected from the jugular vein in heparinised vacutainers (BD

11 Vacutainer ${ }^{\circledR}$ systems, Plymouth, UK) using $21^{\prime} \mathrm{G}$ x 1¹/2” needles.

12 Blood was used in 2 different ways depending on assay:

13 1) Plasma: Full blood was centrifuged for $10 \mathrm{~min}$ at $1500 \mathrm{~g}\left(4^{\circ} \mathrm{C}\right)$. The plasma was aliquoted and

This Supplementary Information:

\section{antioxidant capacity in a wild-living mammal, the European badger (Meles meles)}

\section{to}

r


Following Costantini et al. (2007) and Isaksson et al. (2011), we measured total antioxidant capacity (AOX) as total, non-enzymatic, circulating antioxidants. We used a commercial kit (STA360, Cell Biolabs, San Diego, USA) where antioxidants reduce $\mathrm{Cu}^{2+}$ to $\mathrm{Cu}^{+}$, which reacts with neocuproine to form an orange chromogen measurable at $490 \mathrm{~nm} .20 \mu 1$ of plasma was added to $180 \mu 1$ of reaction buffer in a 96 well plate. Blank absorbance was measured at $490 \mathrm{~nm}$ and $50 \mu 1$ of copper ion reagent was added. The plate was incubated on an orbital shaker for $5 \mathrm{~min}$, before the addition of $50 \mu \mathrm{l}$ of stop solution. Final absorbance was read at $490 \mathrm{~nm}$. To calculate AOX as uric acid equivalent units, blank values were subtracted from the final reading and values were compared to a uric acid standard curve.

\section{Peroxidase (PER) Assay}

We measured PER using a fluorometric assay kit (STA-344, Cell Biolabs, San Diego), where hydrogen peroxide reacts with ADHP in the presence of horseradish peroxidase (HRP) to produce resorufin, which was measured fluorometrically. $50 \mu 1$ of plasma was added to $50 \mu 1$ of reaction mix containing $100 \mu \mathrm{M}$ of ADHP and $\mathrm{H}_{2} \mathrm{O}_{2}$ (2 mM; for peroxidase assay) in the wells of a black 96 well plate (Nunc, Sigma-Aldrich, Dorset, UK). The plate was then incubated in the dark for 30 min before reading the fluorescence (excitation $530 \mathrm{~nm}$, emission $590 \mathrm{~nm}$ ). PER content was then calculated by comparison to a standard curve.

\section{Lipid Peroxidation (LP): Malonaldehyde (MDA) Assay}

We measured LP as the amount of MDA present in the sample using a commercial thiobarbituic acid reactive species (TBARS) assay kit (STA-330, Cell Biolabs, San Diego, USA). The principle of the assay is that two molecules of thiobarbituric acid react with one molecule of MDA (from the sample) to produce a pink molecule with a peak absorbance at $532 \mathrm{~nm}$. Butylated hydroxytoluene (BHT) was then added to samples in a final concentration of $0.05 \%$ to avoid further lipid peroxidation during the assay (Pikul, Leszczynski and Kummerow 1983). Following the manufacturer's protocol for hydrophilic samples, $100 \mu 1$ of plasma, or standard, was incubated 
with $100 \mu \mathrm{l}$ of sodium dodecyl sulphate (SDS) lysis solution for 5 minutes. $250 \mu 1$ of TBA reagent

51 ( $\mathrm{pH}$ adjusted to 3.5) was then added and incubated at $95^{\circ} \mathrm{C}$ for $60 \mathrm{~min}$. Samples were centrifuged

52 for $15 \mathrm{~min}$ at $3000 \mathrm{~g}$, and the supernatant $(300 \mu \mathrm{l})$ was re-suspended in $300 \mu \mathrm{l}$ of $\mathrm{N}$-butanol. This was vortexed for $2 \mathrm{~min}$, followed by centrifugation at 30,000 $\mathrm{g}$ for $5 \mathrm{~min}$. The butanol fractions were transferred to a 96 well plate and absorbance was measured at $532 \mathrm{~nm}$. Concentrations of MDA were then calculated by comparisons to a standard curve.

\section{RBC $1 / 2$-life: Red blood cell killing assay}

57 We used the a red blood cell (RBC) killing assay, to assess the capacity of RBCs to resist lysis in the presence of a strong in vitro oxidant (see Bize et al. 2008). $135 \mu \mathrm{l}$ of $150 \mathrm{mM}$ AAPH $\left(2,2^{\prime}-\right.$

59 Azobis(2-methylpropionamidine) dihydrochloride (Sigma-Aldrich, Dorset, UK) was added to 90

$60 \mu \mathrm{l}$ of diluted RBC. Absorbance was measured spectrophotometerically at $450 \mathrm{~nm}$, every $2.5 \mathrm{~min}$

61 for $3 \mathrm{~h}$. The plate was maintained at $37^{\circ} \mathrm{C}$ for the entirety of the reaction, and the machine was

62 programmed to shake the plate before every measurement to avoid RBC sedimentation. RBC $1 / 2$ -

63 life was calculated by plotting absorbance values against time, and these data were smoothed using

64 a quadratic curve (Fox and Weisberg 2010). Half-life was calculated as the time for the initial absorbance to halve. Mean values were calculated from sample duplicates. Assays were undertaken

66 within $48 \mathrm{~h}$ of blood sample collection.

67

68

69

70

71

72 
74 Table S1 Summary of the first two principal components for the seasonal weather analysis.

\begin{tabular}{|lcc|}
\hline Variable & PC1 & PC2 \\
\hline Eigenvalue & 1.972 & 1.016 \\
\hline \% of variance explained & 65.730 & 33.870 \\
\hline Cumulative \% of variance explained & 65.730 & 99.600 \\
\hline & & \\
& & \\
\hline Minimum temperature & 0.703 & 0.135 \\
\hline Maximum temperature & 0.709 & -0.059 \\
\hline Rainfall & -0.054 & 0.989 \\
\hline
\end{tabular}

75

76

77

78

79

80

81

82

83

84

85

86 
87 Table S2 Summary of the first two principal components of winter weather data for carry-over-

88 effect analyses.

\begin{tabular}{|lcc|}
\hline Variable & PC1 & PC2 \\
\hline Eigenvalue & 3.25 & 0.75 \\
\hline \% of variance explained & 81.24 & 18.76 \\
\hline Cumulative \% of variance explained & 81.24 & 100 \\
\hline & & \\
& & \\
\hline Days of frost & 0.549 & -0.184 \\
\hline Minimum temperature & -0.527 & 0.364 \\
\hline Maximum temperature & -0.556 & 0.025 \\
\hline Rainfall & -0.335 & -0.913 \\
\hline
\end{tabular}

89

90 


\section{Appendix 2}

\section{Details on the Principal Component Analysis (PCA) of weather data, and assessment of autocorrelation}

In this appendix we first provide details on the PCA used to generate the predictive weather variables used in our models as a means of accounting for the collinearity in these data. We then provide details on the assessment of autocorrelation in the fixed effects in these models.

\section{Principal Component Analysis (PCA) of weather data}

The mean seasonal weather data used in our analyses were subject to collinearity. To account for this we used principal component analyses (PCA), conducted with scaling, to transform these data into linearly uncorrelated variables. To do this we applied the prcomp() function from the $\mathrm{R}$ environment to our data on minimum temperature; maximum temperature; and rainfall, with the argument scale $=$ TRUE. The resulting factor loadings for temperature were the most influential contributors to the PC1 axis (see Table A2.1). Loadings for temperature variables were positive, thus higher values of PC1 correspond to higher temperatures. PC2 was dominated by the rainfall data, where this had a positive loading, such that higher values correspond to wetter conditions. These components are henceforth referred to as PCtemp and PCrain in the main text. These two components were retained as the linearly uncorrelated predictive weather variables in our models.

Table A2.1: Summary of the first two principal components of a PCA on seasonal weather data in Wytham Woods, UK, over the study period.

\begin{tabular}{lcc}
\hline Variable & PC1 & PC2 \\
\hline Eigenvalue & 1.972 & 1.016 \\
\% of variance explained & 65.73 & 33.87 \\
Cumulative \% of variance explained & 65.73 & 99.6 \\
& & \\
& & \\
Minimum temperature & 0.703 & 0.135 \\
Maximum temperature & 0.709 & -0.059 \\
Rainfall & -0.054 & 0.989 \\
\hline
\end{tabular}

For our analyses on cary over effects (COE) of winter weather on spring biomarkers of oxidative stress/damage, we conducted a similar PCA, but restricted this to winter weather data. Here, these data also included the variable 'days of frost'. PC1 factor loadings (PCtemp) included maximum temperature, minimum temperature and number of days of frost over the winter, such that higher values of PC1 correspond to lower temperatures and more frost (Table A2.2. PC2 (PCrain) had a negative rainfall loading where higher values correspond to drier weather. 
Table A2.2: Summary of the first two principal components of a PCA on winter weather data in Wytham Woods, UK, over the study period.

\begin{tabular}{lcc}
\hline Variable & PC1 & PC2 \\
\hline Eigenvalue & 3.25 & 0.75 \\
\% of variance explained & 81.24 & 18.76 \\
Cumulative \% of variance explained & 81.24 & 100 \\
& & \\
& & \\
Days of frost & 0.549 & -0.184 \\
Minimum temperature & -0.527 & 0.364 \\
Maximum temperature & -0.556 & 0.025 \\
Rainfall & -0.335 & -0.913 \\
\hline
\end{tabular}

\section{Assessment of autocorrelation}

In addition to issues of collinearity, the fixed effects used in this study (i.e., age class; body condition; and minimum/maximum temperature; and rainfall) are variables that are subject to temporal autocorrelation. If sampled finely enough, any significant autocorrelation in these data would violate the assumption of independence of the linear mixed-effects models used in our analyses. To test for this we quantified autocorrelation functions (ACFs) for time series of the means and variances of these data and assessed whether there was any significant autocorrelation. We did this by first quantifying the means and variances of each of these parameters at each time step using the mean() and $\operatorname{var}()$ functions in the $R$ environment. We note that because we used mean seasonal weather metrics, there was no variance in these data, precluding analysis. Using the $t s()$ function we then converted each of these datasets into a time series and then used the acf() function to quantify the ACF of each time series (see Figures A2.1 and A2.2). Finally, we assessed each ACF for significant autocorrelation. Significance was determined by autocorrelation that exceeded $\pm 2 / \sqrt{(} T)$ where $T$ is the length of the time series (here 8 seasons long).

Notably, because of the coarse temporal scale at which these data were measured, there was no significant autocorrelation in any of the fixed effects used in our analyses. 

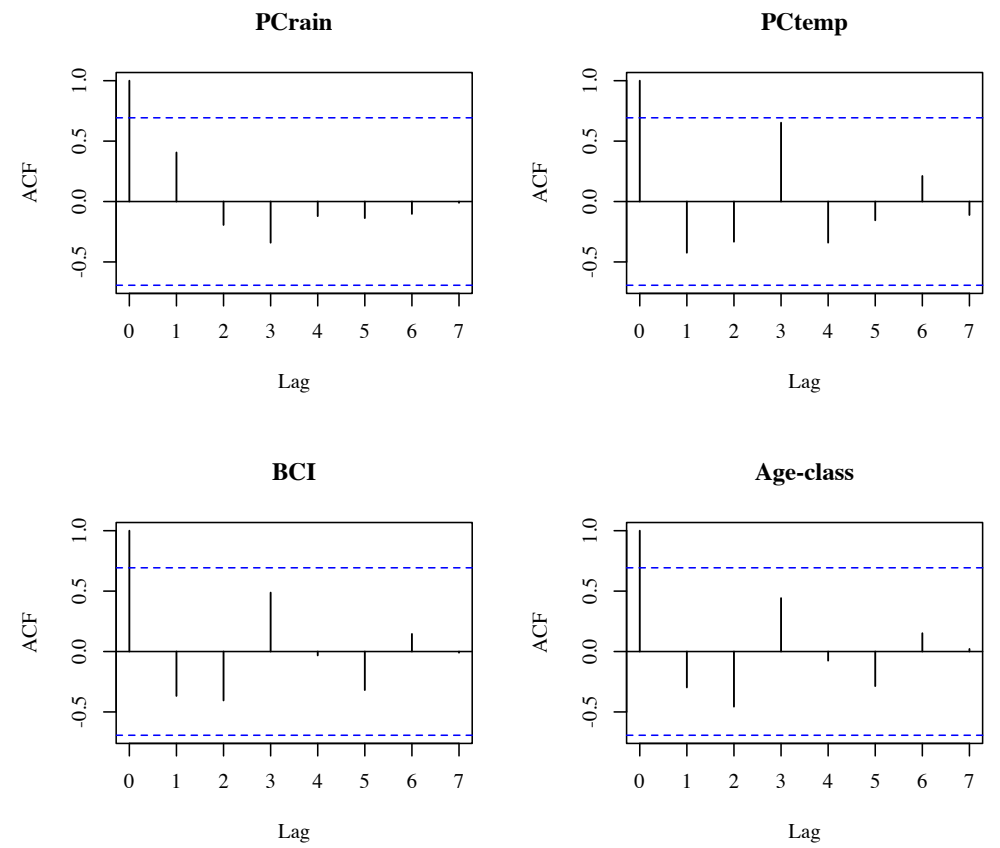

Figure A2.1: Time lagged autocorrelation in the means of the fixed effects used in our linear models. In all panels the blue dashed line depicts the significance threshold. Notably, there was no significant autocorrelation in any of these data.
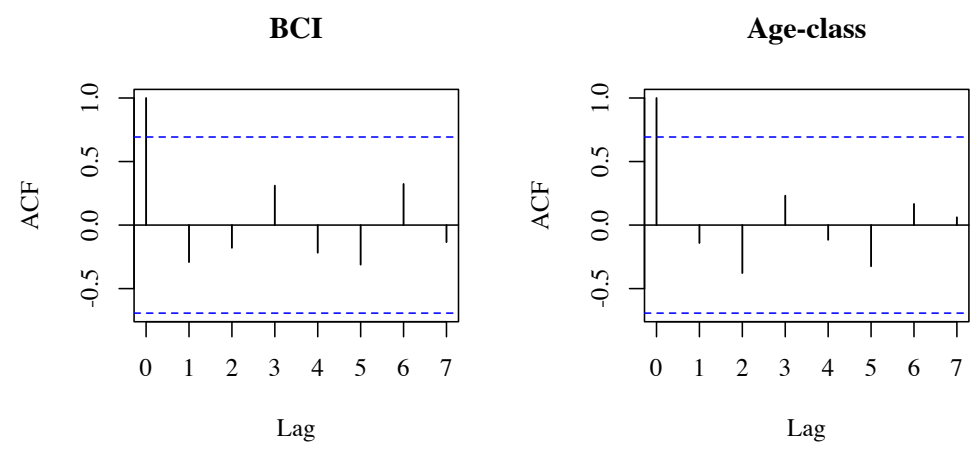

Figure A2.2: Time lagged autocorrelation in the variance of the fixed effects used in our linear models. In all panels the blue dashed line depicts the significance threshold. Notably, there was no significant autocorrelation in any of these data. 
Re: PBZ-17099R1

Reviewer 1 Comments

You have done a great work with the revision. Some sections in the results need further attention and I hope that my comments below will be helpful in the revised MS.

Thanks once more for your careful attention to our manuscript, and especially for noticing that our column headers in Tables 4 and 5 had become changed to white, and were thus invisible. Throughout we have implemented your recommendation that we are dealing with predictions, rather than hypotheses.

We feel our manuscript is much improved, thanks to your input.

Abstract

The take home message is improved compared to the first submission but it is still too general.

Unfortunately, to summarise one biomarker more specifically rather imposes that we should do so for all, and this approach instantly takes us over word limits. There is rather a lot to squeeze into the Abstract (age, sex, weather, biomarker effect, COE, etc) and so it does inevitable have to skim the discoveries made rather superficially, given that we also have to provide a conceptual framework for our work. We hope you think the Abstract is adequate.

L68 suggest to change to energetics needs instead of caloric needs

Done

L80 -96 , I think that these are all predictions and not hypotheses because you indicate a direction for the response.

OK changed to 'we predict'.

L182 should be "in following the spring" in the following spring?

I think there is perhaps a misunderstanding here. We do indeed mean in the following (ie subsequent) spring that follows after the winter - ie the carry over effect of the winter is observed in the 'following spring'. Nothing here 'follows the spring'. I hope this is clear.

$\mathrm{L} 186$ Is the model weight is the same as the Akaike weight $(w)$ for you calculated using the $R$ package MuMIn (v. 1.15.6; Barton 2016)?

Correct. For complete clarity we have added: "...Akaike (or model) weight (w) for each model..." 
L 249-255: The information is descriptive. Where it is shown (no reference in the text to table or figure). Where these changes significant?

Antioxidant enzymes - peroxidase (PER) - no reference in the text to table or figure and indicate if the trend in PER (L259) was significant or not.

The model was significant, as described under the sub-heading 'Antioxidant Capacity-AOX', with statistical values given in Table 4, as stated in the text.

Apologies for oversight on PER, we have added (Table 4) and reference to (Figure 1) for each biomarker [all stats outputs are shown in Table 4].

L262- 267: Where it is shown (Table 4?), please refer to the stat. Where the high and low interindividual variation is shown and how do you define high and low?

The Stat is given in Table 4. Inter-individual variation are depicted by the \pm standard deviations provided in Table 3 (now specified in the text).

Note, we do not define inter-individual variation in absolute terms, and therefore not as either 'high' or 'low'. Rather we examine inter-individual variation in relative terms, talking about circumstances where it is 'higher' or 'lower'.

L278-282: Where it is shown (Table 4?), please refer to the stat.

Yes - we were remiss in not repeating that each model statistic is presented in Table 4. We have added this throughout, as necessary.

L284-290: Where it is shown?

Table 4 - added.

L291-292 Delete

Respectfully, we would like to retain the RBC $1 / 2$-life results for adults, even though there were no clear patterns, for consistency of reporting relative to other biomarker sections.

L305-313, Pool the sections to one section and refer to the relevant table or figure.

Respectfully, we would like to retain this sub-heading format for consistency and easy comparison to the preceding section.

We had mentioned that Figure 2 and Table 5 pertained to these COE results under first subheading $(A O X)$, and hoped that it would be clear that the same Figure and Table depicted results from other biomarkers (so as not to burden the text). Acknowledging your concern about short segments here, rather than add (Figure 2; Table 5) to each biomarker, instead we have specified that all biomarker statistics refer to Figure 2 and Table 5 at the start of this section (end of "Analysis of COE..." section).

L348 In support of our third hypothesis, carry-over effects: add (COE) 
Actually, there seems little point in specifying an acronym and then not using it, and so we considered just using COE here; however, because this is the first mention in the Discussion we thought it best to write it out in full, but that repeating the already-defined acronym could be redundant. Nevertheless, for total clarity, we have added it as you suggest.

ALSO- with respect to your recommendation in the Into that we should phrase our 'hypotheses' as 'predictions', we have also changed phrasing to 'predictions' in the Discussion, for consistency.

L383 inter-individual variation, see my previous comment.

See accompanying response. Depicted by the Standard Deviation in Table 3, but we think this is now clear from revision to the Results section, without adding table cross-references to the Discussion.

L398, this is your sixth hypothesis: "cub may experience more severe OS/OD effects in years with more extreme weather"

Correct, our $6^{\text {th }}$ 'prediction', as stated.

Notice that you may mix between hypothesis and predictions in the discussion. In line 368 you mention hypothesis "third hypothesis" and in line 363 you mention prediction. See also my earlier comment.

Noted, and we accept that indeed strictly we do phrase these as predictions, and we have amended our phrasing accordingly.

Table 4 and 5: All measured biomarkers should appear in the top line (first line of the table). Right now, they are missing from both tables.

Well spotted - thank you. For reasons I don't understanding, these headings had changed to white font on a white background - now restored to default black.

Reviewer 3 Comments

My major concerns have been carefully addressed by the authors. The manuscript has been greatly improved.

We are sincerely grateful for your input and for your approval of our revision, which has benefited enormously from your advice. 
